\title{
Dispersion of traffic-related exhaust particles near the Berlin urban motorway - estimation of fleet emission factors
}

\author{
W. Birmili ${ }^{1}$, B. Alaviippola ${ }^{2,1}$, D. Hinneburg ${ }^{1}$, O. Knoth ${ }^{1}$, T. Tuch ${ }^{1,3}$, J. Borken-Kleefeld ${ }^{4, *}$, and A. Schacht ${ }^{4}$ \\ ${ }^{1}$ Leibniz Institute for Tropospheric Research (IfT), Permoserstrasse 15, 04318 Leipzig, Germany \\ ${ }^{2}$ Finnish Meteorological Institute (FMI), P.O. Box 503, 00101 Helsinki, Finland \\ ${ }^{3}$ Helmholtz Center for Environmental Research - UfZ, Permoserstrasse 15, 04318 Leipzig, Germany \\ ${ }^{4}$ German Aerospace Center (DLR), Transportation Research, Rutherfordstrasse 2, 12489 Berlin, Germany \\ *now at: International Institute for Applied Systems Analysis, Schlossplatz 1, 2361 Laxenburg, Austria
}

Received: 23 May 2008 - Published in Atmos. Chem. Phys. Discuss.: 15 August 2008

Revised: 25 March 2009 - Accepted: 25 March 2009 - Published: 2 April 2009

\begin{abstract}
Atmospheric particle number size distributions of airborne particles (diameter range $10-500 \mathrm{~nm}$ ) were collected over ten weeks at three sites in the vicinity of the A100 urban motorway in Berlin, Germany. The A100 carries about 180000 vehicles on a weekday. The roadside particle distributions showed a number maximum between 20 and $60 \mathrm{~nm}$ clearly related to the motorway emissions. The average total number concentration at roadside was $28000 \mathrm{~cm}^{-3}$ with a total range of $1200-168000 \mathrm{~cm}^{-3}$. At distances of 80 and $400 \mathrm{~m}$ from the motorway the concentrations decreased to mean levels of 11000 and $9000 \mathrm{~cm}^{-3}$, respectively. An obstacle-resolving dispersion model was applied to simulate the 3-D flow field and traffic tracer transport in the urban environment around the motorway. By inverse modelling, vehicle emission factors were derived that are representative of a fleet with a relative share of $6 \%$ lorry-like vehicles, and driving at a speed of $80 \mathrm{~km} \mathrm{~h}^{-1}$. Three different calculation approaches were compared, which differ in the choice of the experimental winds driving the flow simulation. The average emission factor per vehicle was $2.1( \pm 0.2) \cdot 10^{14} \mathrm{~km}^{-1}$ for particle number and $0.077( \pm 0.01) \cdot 10^{14} \mathrm{~cm}^{3} \mathrm{~km}^{-1}$ for particle volume. Regression analysis suggested that lorry-like vehicles emit $123( \pm 28)$ times more particle number than passenger car-like vehicles, and lorry-like vehicles account for about $91 \%$ of particulate number emissions on weekdays. Our work highlights the increasing applicability of 3-D flow models in urban microscale environments and their usefulness for determining traffic emission factors.
\end{abstract}

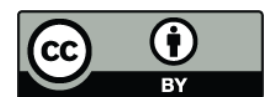

Correspondence to: W. Birmili (birmili@tropos.de)

\section{Introduction}

Clear associations have been found between ambient particular matter (PM) and adverse health effects in humans (Künzli et al., 2000; Pope et al., 2002). It is a hypothesis that the health effects observed in broad parts of the population may be caused by a particular sub-fraction of PM rather than total PM mass (HEI, 2002). Epidemiological evidence has related respiratory disease with ultrafine particles, i.e. with diameters $<100 \mathrm{~nm}$ (Schwartz et al., 1996; Peters et al., 1997), or with traffic-related emissions in general (Brunekreef et al., 1997; Kim et al., 2004).

A number of arguments point towards the possible induction of health effects by traffic aerosols: The mere small size of ultrafine particles could lead to a deep penetration into the lung, and subsequent irritations in the alveolar region, where ambient air is in exchange with the blood circulation (Seaton et al., 1995). Furthermore, particulate traffic emissions contain high numbers of insoluble particles, such as diesel soot (Weingartner et al., 1997; Rose et al., 2006). Such particles are only poorly removed from the lung. Engine emissions tend to contain organic toxins (PAHs) and a myriad of other so far unidentified micropollutants (e.g., Spurny, 1999; Gelencser, 2004).

Motor vehicles inject a wide spectrum of particles into the atmosphere. While coarse particles may be emitted directly through break wear, and indirectly by road dust resuspension, fine particles are primarily emitted in the form of combustion engine exhaust. Modern engines tend to emit less particle mass, but this is not necessarily true for particle number (Ntziachristos et al., 2004). Most of particle number, especially in gasoline vehicle emissions, has been found in

Published by Copernicus Publications on behalf of the European Geosciences Union. 
the ultrafine size range (Kean et al., 2003). Recent measurements of a representative cross-section of passenger cars by Samaras et al. (2005) during the EU Commission Particulates Programme confirmed that diesel engines without particulate diesel filter emit significantly more PM mass, and also particle number than conventional gasoline vehicles. Mass emissions from gasoline cars still vary considerably with engine technology. Mass emissions from conventional gasoline engines are about three orders of magnitude lower than diesel cars without diesel particulate filter, but direct injection gasoline engines (Euro III norm) are only one order of magnitude lower. Dynamometer tests showed that the diameter of maximum particle number concentration of diesel exhaust particles lies mostly in the region between 60 and $80 \mathrm{~nm}$, however, depending on the engine technology and the state of driving (Ntziachristos et al., 2004; Samaras et al., 2005).

Diesel particulate filters seem to reduce the emissions of diesel cars to those comparable to conventional gasoline cars (Burtscher, 2005). Heavy duty engines were found to behave similar to passenger car diesel engines, and showed decreasing mass emission rates with improving engine technology (Mayer et al., 2007). As the particulate mass emission rate increases in proportion with the engine power, heavy duty vehicles may emit the multiple of emissions of a conventional passenger car. Nucleation mode particles $<50 \mathrm{~nm}$ tend to be created by all engine types especially at high driving speeds (i.e. high engine loads) and with sulphur-rich fuel. Even vehicles equipped with diesel particulate filters may emit particle numbers considerably above ambient levels (Ntziachristos et al., 2004; Samaras et al., 2005).

Dynamometer experiments highlighted that the concentration of the nucleation mode depends on the dilution process of the sampled exhaust gas (Kittelson, 1998; Mathis et al., 2004). When vehicles are driven on real roads, new particles may be formed downstream the exhaust pipe, i.e. when hot exhaust gas cools down and causes nucleation of sulfuric as well as unburnt organic fuel compounds. On the road, this nucleation mode could be detected already $5 \mathrm{~m}$ behind vehicles (Ronkko et al., 2006). The underlying nucleation depends on temperature as well as vehicle-induced turbulence and cannot necessarily be reproduced by dynamometer measurements. It is evident that the role of aerosol dynamical processes grows with increasing proximity to the exit of the exhaust pipe (Pohjola et al., 2003; Zhang and Wexler, 2004). The ubiquity of traffic-related nucleation particles and their relevance to outdoor concentrations have been confirmed by many observations in roadside environments (Zhu and Hinds, 2002; Wehner et al., 2002; Charron and Harrison, 2003; Hussein et al., 2004; Rosenbohm et al., 2005; Voigtländer et al., 2006).

In order to capture the full impact of traffic-generated particles on the environment, atmospheric experiments near traffic sources are required, particularly in combination with a numerical assessment of particle dispersion and transport as well as aerosol dynamical processes. Numerous works have dealt with pollutant dispersal in simplistic configurations of urban landscapes, such as street canyons, and relatively accurate descriptions for these scenarios have been developed and experimentally verified (Vardoulakis et al., 2003; Holmes and Morawska, 2006). While most of the local fluid mechanical processes in an urban landscape are understood, the most appropriate framework to study and quantify dispersal in the case of extended, more irregular topographies is less clear (Britter and Hanna, 2003). In several cases, however, three dimensional fluid dynamics models have already been applied to describe pollutant dispersal in irregular urban landscapes (Schlünzen et al., 2003; Wissink et al., 2005).

This paper reports on ambient measurements of sub- $\mu \mathrm{m}$ particle size distributions in the vicinity of the A100 urban motorway in Berlin, Germany. We apply a 3-D micrometeorological model to simulate dispersion of traffic emissions downwind the motorway. The particle measurements are combined with vehicle counts and meteorological dilution factors to derive real-world and size-segregated emission factors for the entire fleet, as well as passenger cars and lorries separately.

\section{Experimental methods}

\subsection{The A100 motorway field experiment}

Sub- $\mu \mathrm{m}$ particle number size distributions were measured between July and September 2005 during 10 weeks in the vicinity of the A100 Berlin urban motorway. Measurements were carried out several kilometres west of Berlin's city centre in the district of Westend $\left(52^{\circ} 31^{\prime} \mathrm{N}, 13^{\circ} 17^{\prime} \mathrm{E}\right)$, an area densely build-up with multi-storey residential buildings (see Fig. 1). Particle size distributions were collected simultaneously at three measurement sites with different distances and in different directions from the motorway. The A100 motorway carries about 180000 vehicles on 6 lanes per working day and traverses the area through a traffic corridor about $100 \mathrm{~m}$ wide that includes the Berlin circular urban railway. Although the motorway is the overwhelming source of traffic-generated aerosols, several secondary roads lead through the area, notably the Spandauer Damm street, which crosses the motorway perpendicularly in east-westerly direction.

\subsection{Particle measurement sites}

The roadside measurement site was the one in closest proximity to the motorway (Fig. 1). As the measurement site had been previously used by the Berlin city council as a part of the communal air quality monitoring system, it had already a pre-existing cabin infrastructure. Immediately to the north of the roadside site, slip roads lead to the Spandauer Damm street that crosses the motorway further north. The aerosol inlet was located $4 \mathrm{~m}$ off the pavement of the motorway horizontally, and $6 \mathrm{~m}$ vertically. Size distribution measurements 


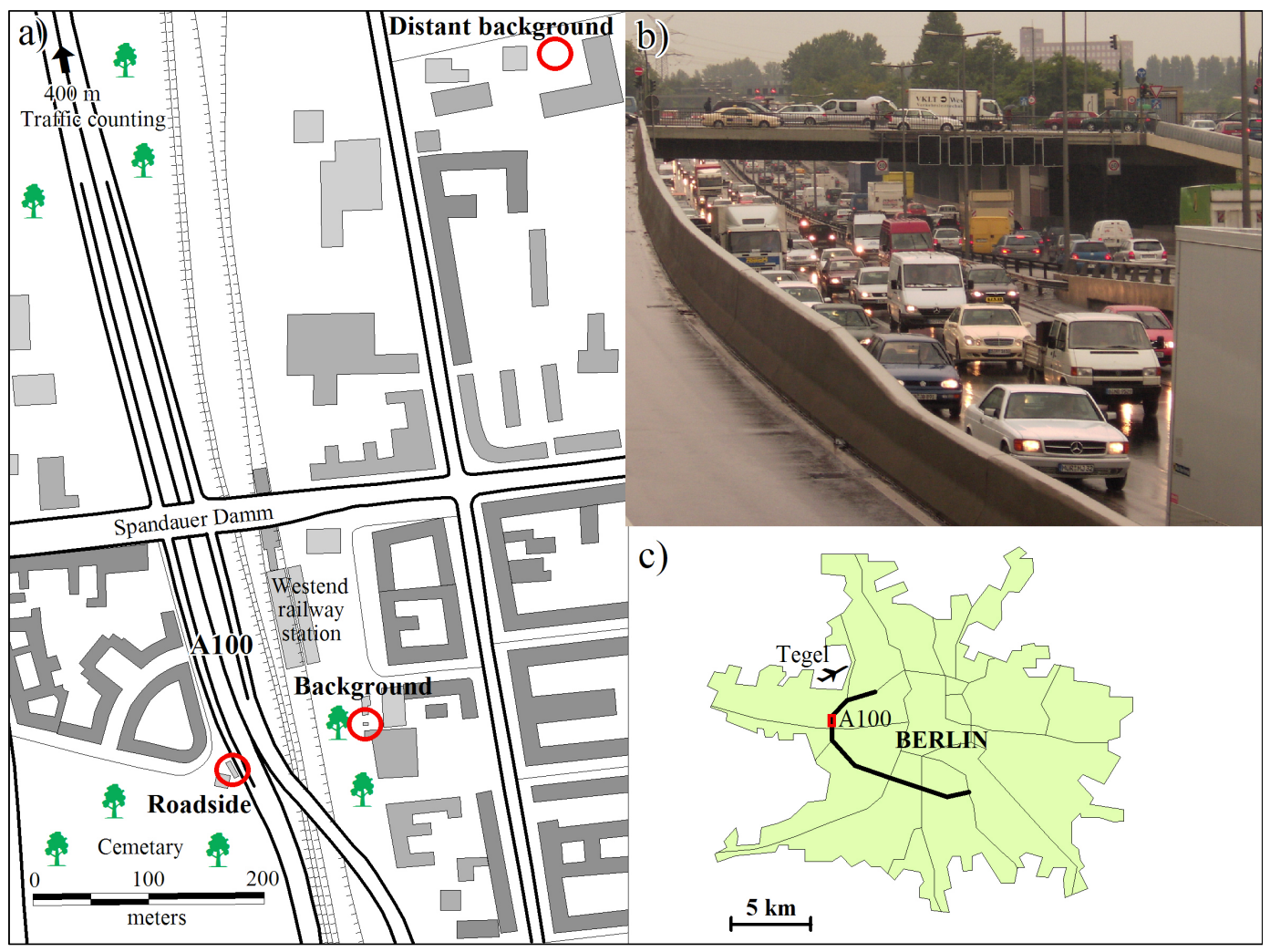

Fig. 1. (a) The surroundings of the A100 motorway including the locations of aerosol measurement and traffic count sites. (b) Traffic on the motorway near Spandauer Damm bridge. (c) Situation of the motorway and Tegel Airport within Berlin.

lasted from 29 June until 5 September 2005. The auxiliary measurements included local wind speed and wind direction using a cup anemometer as well as ambient temperature, relative humidity and air pressure on hourly averages.

The first background measurement site (termed "background site" in the following) was located about $80 \mathrm{~m}$ east of the motorway, therefore serving as a site more downstream of the source than the roadside site. South of the background site, the two three-lane carriageways of the A100 split, and the easterly (northbound) carriageway is conducted on a flyover in order to cross the Berlin circular urban railway. Therefore, the background site was located approximately $10 \mathrm{~m}$ below the more closely situated carriageway. Between the motorway and the background site, electrified suburban trains circulate as the only possible additional source of particles. Measurements were performed from inside a temporarily located measurement trailer with an aerosol inlet $6 \mathrm{~m}$ above the ground. Size distribution measurements lasted from 30 June until 2 September 2005. Further measurements at the site included wind speed and wind direction with an ultrasonic anemometer (model USA-1, Metek Inc., Elmshorn, Germany).

A second background measurement site (dubbed "distant background site" in the following) was located about $400 \mathrm{~m}$ distant from the motorway, and designed to be a background station to both other sites. Measurements were made from inside a laboratory van and included particle size distribution, nitrogen oxide and dioxide and meteorological measurements. Size distribution measurements at the distant background site lasted between 5 July and 10 August 2005 .

Additional resources include wind speed and wind direction data measured by the German Meteorological Service DWD at the airport Berlin-Tegel, located about $4 \mathrm{~km}$ north of the area (Fig. 1c). The Tegel winds were recorded at a height of $10 \mathrm{~m}$ above flat ground and therefore utilized as an indicator of the large scale wind.

\subsection{Particle mobility spectrometers}

Ambient particle number size distributions were recorded continuously at each of the measurement sites. The instrumentation used included two main types of particle mobility spectrometers. The background site was equipped with a Twin Differential Mobility Particle Sizer (TDMPS) covering a particle diameter range between 3 and $900 \mathrm{~nm}$. The TDMPS is a custom made instrument similar to that described in Birmili et al. (1999). Briefly, two Vienna type differential mobility analysers (DMA; Winklmayr et al., 1991) were deployed having centre rod lengths of 11 and $28 \mathrm{~cm}$, respectively. The sheath air in the two DMAs was 
circulated in a closed loop using spin-regulated blowers. The sheath/aerosol flow ratio in the two DMAs was 20/2.0 and $5.0 / 0.51 \mathrm{~min}^{-1}$, respectively. The relative humidity inside the system was kept under $30 \%$.

The roadside and distant background sites, on the other hand, were equipped with Scanning Mobility Particle Sizers (SMPS model 3080 with long DMA; TSI Inc., St Paul, USA) operated at a sheath air ratio of $5.0 / 0.51 \mathrm{~min}^{-1}$. Both systems used a model 3010 condensation particle counter operated at the standard flow rate $1.01 \mathrm{~min}^{-1}$. The particle size range covered by these instruments was $10-500 \mathrm{~nm}$. The relative humidity inside the SMPS instruments could not be actively controlled, but was estimated to be within $20-40 \%$.

To ensure a maximum comparability of the size distributions determined at different sites, direct comparison experiments using the same ambient sample aerosol were performed over several days before and after the campaign. Among the systematic deviations identified between different instruments were (a) the measured overall particle concentration and (b) the instrumental number concentration response as a function of particle diameter. Both of these effects were corrected for each instrument when evaluating the final data. Since the TDMPS instrument is least affected by particle losses in the ultrafine range $(<20 \mathrm{~nm})$ the data measured by both TSI instruments was corrected upwards. We estimate that the corrected particle concentrations inferred from each instrument across the size spectrum 10-600 nm are comparable within $\pm 10 \%$.

In the field, none of the instruments was equipped with an inlet buffer volume. The lack of such a buffer volume may hypothetically cause the measured size distributions to diverge systematically, since the ambient aerosols at roadside tend to fluctuate much faster than a size distribution measurement cycle (4 min). To assess this issue, a sensitivity analysis was carried out by modulating random oscillations onto the raw mobility distributions before the multiple charge inversion. Fortunately, we found that the oscillations did not change the mean values of the inverted particle size distributions by more than $2 \%$ based on a sample number of 50 . In conclusion, statistically averaged size distributions depend only weakly on whether choosing a buffer volume or not.

\subsection{Traffic counts}

The traffic on the A100 motorway is routinely counted about one kilometre north of the particle sampling site. The detectors TT292 of ASIM combine radar, ultrasound and passive infrared monitoring to count the vehicles on each lane separately. Vehicles are identified by shape and classified into two length classes, shorter and longer than $6.5 \mathrm{~m}$. The shorter length class is comprised of motorcycles, passenger cars, vans and minibuses, sport utility vehicles and delivery vans. The longer length class comprises lorries, busses, and vehicle combinations (i.e. including trailers). This size information is in the following used to distinguish between "passenger car-like vehicles" and "lorry-like vehicles". The lorry-like class comprises, in any case, what is known as heavy-duty vehicles (HDV). Low-duty vehicles (LDV), such as transportation vans, tend to be included within the passenger car-like class. Measurements for the period between 28 June and 5 September 2005 were used here.

The detectors simultaneously measured the number and speed of the vehicles passing during each second. An accuracy of classification between 98 and $99 \%$ is given for both length classes on a minute and hourly average. Misdetection may occur due to lane crossing and in case of congested traffic; then the size resolution may be flawed. This traffic counting site is the most accurate and closest to the roadside and background measurement sites. However, there is a motorway exit and access point at Spandauer Damm in between. Hence the number of southbound vehicles passing the roadside and background measurement sites equals the number of vehicles at the traffic counting site minus the vehicles having exited plus the vehicles entering at Spandauer Damm. For the northbound traffic the conditions are inverse. In order to establish the balance of entering and leaving vehicles, we therefore counted the traffic manually at that site during a short follow-up experiment (27 March 2007).

The distance between traffic counting site and particle measurement site implies a slight time lag: At an average speed of $80 \pm 20 \mathrm{~km} \mathrm{~h}^{-1}$ southbound vehicles pass the traffic counting site about $45 \pm 15 \mathrm{~s}$ earlier than the particle measurement sites; northbound they are counted this time later. Since emission factors of the vehicular fleet will later be derived on the basis of one hour data averages, this short delay can safely be neglected.

\section{Modelling technique}

\subsection{3-D dispersion modelling}

The micro-scale atmospheric model ASAM (All-Scale Atmospheric Model; Hinneburg and Knoth, 2005) is used to simulate the three-dimensional dispersion of an inert tracer, i.e. without physical and chemical transformations, in the surrounding of the measuring sites. The prognostic, nonhydrostatic, and inelastic model solves the conservation equations for momentum, turbulent kinetic energy and dissipation, potential temperature, moist constituents as well as inert tracers by third-order implicit techniques. The model adopts the standard $\mathrm{k}-\epsilon$-turbulence model of firstorder closure with shear and buoyant production terms and the constant-flux approach on the walls and the surface.

In ASAM the orography as well as all obstacles, i.e. buildings, bridges, and ramps, are explicitly represented by completely or partially (with inclined surfaces) filled grid cells in a rectangular Cartesian $z$-coordinate system (not terrainfollowing). Figure 2 shows the relatively complex model domain with a raised surface as well as an outstanding 


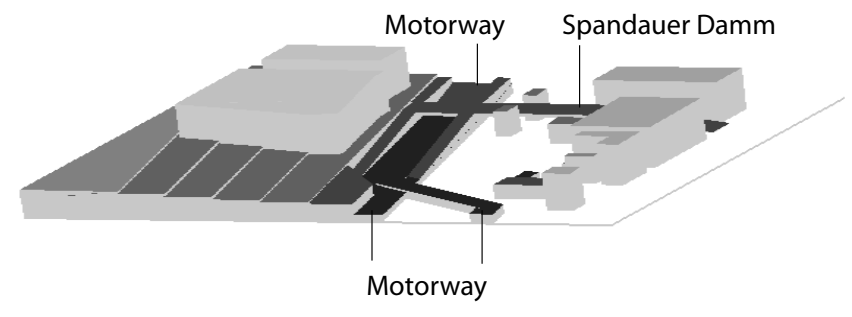

Fig. 2. 3-D model domain with the A100 motorway in black.

building block immediately west of the motorway. The lowered northern part of the motorway passes under a long bridge (Spandauer Damm), while the southern part splits in two disjoined lanes. The model was applied to a region of $500 \mathrm{~m} \times 500 \mathrm{~m}$ with $5 \mathrm{~m}$ horizontal grid spacing. Its vertical extension was $100 \mathrm{~m}$ with the vertical grid resolution varying from $2 \mathrm{~m}$ in the obstacle layer to $10 \mathrm{~m}$ at the model top. Traffic emissions were implemented as constant area sources in grid cells adjacent to the lanes of the motorway. Neutral temperature profiles and a uniform roughness of $0.10 \mathrm{~m}$ for the surface and the walls were assumed.

A total of ten simulations - essentially corresponding to ten different directions of the driving wind, was conducted. This set of simulations was subsequently generalised for arbitrary wind speeds and source intensities by appropriate scaling relations (Palmgren et al., 1999; Ketzel et al., 2003). A first approximation is that all local wind speeds $u$ scale linearly with the diving wind speed $U$. Secondly, we expect the local concentrations $c$ to scale linearly with the source intensity $Q$, but inversely with $U$ (dilution effect).

The normalised local wind speed $u^{*}$ (non-dimensional) is defined as:

$u^{*}=\frac{u}{U}$,

with $u$ being the local wind speed and $U$ the large scale wind speed far from the surface $(h=100 \mathrm{~m})$. See also Table 1 for a nomenclature of all variables used in this paper. The normalised local concentration $c^{*}$ (non-dimensional) is defined as:

$c^{*}=\frac{c \cdot U \cdot H}{Q}$,

where $c$ is the local tracer concentration (in $\mathrm{m}^{-3}$ ) induced by the emission source, $Q$ the line source intensity in $\mathrm{m}^{-1} \mathrm{~s}^{-1}$, and $H$ the characteristic obstacle height (concretely $H=40 \mathrm{~m}$, the maximum height of the street canyon). $Q$ indicates the number of particles emitted in one second per metre of road.

\subsection{Vehicle emission factors}

Vehicle emission factors were determined by applying micrometeorological dilution factors from the dispersion simulations upon the experimental data collected at roadside. This
Table 1. Nomenclature of variables used in this paper, with their physical SI units and the units used here.

\begin{tabular}{|c|c|c|c|}
\hline & & SI & here \\
\hline$U$ & large-scale wind speed & $\mathrm{ms}^{-1}$ & $\mathrm{~ms}^{-1}$ \\
\hline$u$ & local wind speed & $\mathrm{ms}^{-1}$ & $\mathrm{~ms}^{-1}$ \\
\hline$u^{*}$ & local wind speed (normalised) & 1 & 1 \\
\hline$c$ & particle number concentration & $\mathrm{m}^{-3}$ & $\mathrm{~cm}^{-3}$ \\
\hline$c^{*}$ & $\begin{array}{l}\text { particle number concentration } \\
\text { (normalised) }\end{array}$ & 1 & 1 \\
\hline$h$ & height of the modelling domain & $\mathrm{m}$ & $\mathrm{m}$ \\
\hline$H$ & characteristic obstacle height & $\mathrm{m}$ & $\mathrm{m}$ \\
\hline$Q$ & line source intensity & $\mathrm{m}^{-1} \mathrm{~s}^{-1}$ & $\mathrm{~m}^{-1} \mathrm{~s}^{-1}$ \\
\hline$M$ & traffic density & (veh.) $\mathrm{s}^{-1}$ & (veh.) $\mathrm{s}^{-1}$ \\
\hline$F$ & dilution factor & $\mathrm{s} \mathrm{m}^{-2}$ & $\mathrm{~s} \mathrm{~m}^{-2}$ \\
\hline$\eta$ & scaling constant & 1 & 1 \\
\hline$E_{N}$ & $\begin{array}{l}\text { particle number emission factor } \\
\text { (veh. }^{-1} \text { ) }\end{array}$ & $\mathrm{m}^{-1}$ & $\mathrm{~km}^{-1}$ \\
\hline$E_{V}$ & $\begin{array}{l}\text { particle volume emission factor } \\
\text { (veh. }^{-1} \text { ) }\end{array}$ & $\mathrm{m}^{3} \mathrm{~m}^{-1}$ & $\mathrm{~cm}^{3} \mathrm{~km}^{-1}$ \\
\hline
\end{tabular}

general method has been dubbed "inverse modelling" (Ketzel et al., 2003). Since our transport simulation does not describe physical and chemical particle transformations, the calculation of an emission factor requires the particles to be inert (i.e. non-reactive) during the transport between the source and the receptor point. Coagulation is an important process in highly concentrated aerosols, and we tested the life-time of aerosol particles at the roadside site with respect to coagulation (see Appendix). The life-times were on the scale of $10 \mathrm{~min}$ and more for average conditions, i.e. sufficiently long to take the derived emission factors as representative for the emission flux through the envelope of the motorway as a line source.

The inverse modelling approach yields the emission factor $E$ (in veh ${ }^{-1} \mathrm{~km}^{-1}$ ), which indicates the number of particles emitted by the vehicle fleet per kilometre driven under the prevailing traffic flow conditions. $E$ is defined as:

$E=\frac{Q}{M}$,

with $Q$ being the line source intensity (Sect. 3) and $M$ the traffic volume in veh $\mathrm{s}^{-1}$. Particle dispersion downwind the traffic source is described by the dilution factor $F$, having units of $\mathrm{s} \mathrm{m}^{-2}$ :

$F=\frac{c}{Q}$

Here, $c$ is the roadside increment concentration in particles $\mathrm{m}^{-3}$. For the roadside site, this roadside increment was calculated as $c$ (roadside)- $c$ (background). When combining Eqs. (2) and (4) the dilution factor $F$ can be reformulated as:

$F=\frac{c^{*}}{U \cdot H}$ 
In this equation, $U$ can be replaced by the experimental $\bar{U}$. Since $U$ refers to the driving wind of the simulation at a height of $100 \mathrm{~m}$, its experimental replacement $\bar{U}$ needs to correspond to the same height. $\bar{U}$ was determined from wind speed measurements at Tegel airport ( $10 \mathrm{~m}$ above the surface) by scaling the measured value according to simulated vertical wind profiles. A scaling factor $\bar{U}(100 \mathrm{~m}) / \bar{U}(10 \mathrm{~m})$ of 1.5 was chosen, which was calculated on the basis of a logarithmic wind profile and an estimated roughness length of $0.1 \mathrm{~m}$ at Tegel airport.

After combining Eqs. (3), (4) and (5), importing the experimental data, and substituting experimental $\bar{c}^{*}$ with modelled $c^{*}$ the emission factor $E$ becomes:

$E=\frac{\bar{c} \cdot \bar{U} \cdot H}{\bar{M} \cdot c^{*}}$,

with barred variables representing experimental values. In this equation the emission factor is calculated as a function of the large scale experimental wind.

To check the reliability of the substitution of $U$ by $\bar{U}$, we analysed a scaling relationship between measured and modelled wind speeds by defining a scaling constant:

$\eta=\frac{\bar{u}}{\bar{U}} \cdot \frac{U}{u}$.

Here, $\bar{u} / \bar{U}$ is the ratio of the experimental local and large scale wind speeds and $u / U$ the corresponding modelled wind speed ratio. Concretely, $\eta$ expresses the degree of correspondence between experiment and simulation and will, in practice, depend on several factors including wind direction. $\eta=1$ implies an identical ratio between the local and large scale winds both, in the experiment and the simulation. Concrete values of $\eta$ were calculated for different wind directions by fitting linear trend lines to scatter plots of $\bar{u}$ against $\bar{U}$. (To eliminate any bias caused by calm wind situations, only data with Tegel wind speeds $>2 \mathrm{~m} \mathrm{~s}^{-1}$ were accepted.) For the roadside site, an average $\eta$ of 0.63 (total range 0.30 1.19) was calculated, i.e., the experimental wind is on average slower than predicted by the simulation. For the background site, $\eta$ was determined to be 0.30 (total range $0.23-$ 0.38 ), i.e. the experimental winds were disproportionately lower than the simulated ones. It came to our impression that this discrepancy was caused by individual roughness elements (trees) around the background site, which were not considered explicitly in the model (see Sect. 5.2 below).

Combining Eqs. (1), (6) and (7), the emission factor $E$ can be described as:

$E=\frac{\bar{c} \cdot \bar{u}}{\bar{M} \cdot\left(c^{*} u^{*}\right) \cdot \eta}$

where $c^{*} u^{*}$ is the product of the normalised variables $c^{*}$ and $u^{*}$ Eq. (8) is a variant of Eq. (6) where eventual winddirectional dependencies of the relationship between the local and large scale wind speeds are accounted for.
A third approach for $E$ is to use Eqs. (1) and (6) before importing the experimental data, and associate experimental $\bar{c}^{*} \bar{u}^{*}$ with modelled $c^{*} u^{*}$

$E=\frac{\bar{c} \cdot \bar{u} \cdot H}{\bar{M} \cdot\left(c^{*} u^{*}\right)}$

The essential difference between Eqs. (6) and (9) is that the product $c^{*} u^{*}$ is, in contrast to $c^{*}$, independent of the particular choice of $U$, the driving wind speed at the top of the model domain. (Recall that $U$ could not be measured directly but had to be constructed from the measurement at $h=10 \mathrm{~m}$ at Tegel.) In short, the calculations based on Eq. (9) are driven by the locally measured wind speeds rather than in Eq. (6), where an experimental large-scale wind is used.

Fleet emission factors were calculated as a function of experimental and simulated parameters according to Eqs. (6), (8) and (9). Due to restricted computing time, $u^{*}, c^{*}$ and $c^{*} u^{*}$ were calculated for 10 discrete wind directions only. To provide values as a continuous function of large-scale wind direction, they were linearly interpolated.

As a quality control measure, some sections of data were removed before the discussion of the calculated emission factors (Sect. 6.1). This concerned $50 \%$ of the data recorded during calm winds - defined as Tegel wind speeds below $2 \mathrm{~m} \mathrm{~s}^{-1}$. We assume that under calm winds the transport model will not represent the local dispersion conditions accurately, either due to a weak coupling between large-scale and local winds, or to the increasing importance of vehicleinduced turbulence, which is neglected in the model, with decreasing wind speed. A second quality control measure was the selection of particular wind directions $\left(330-150^{\circ}\right)$, notably those that place the roadside receptor site downwind of the motorway.

\section{Field observations}

\subsection{Traffic counts}

On weekdays (Mondays to Fridays) about 180000 ( \pm 17000$)$ vehicles passed by the traffic counting facility during the period between 28 June and 5 September 2005 (see Table 2). Lorry-like vehicles made up about $6 \%$ of this volume. Almost $90 \%$ of all vehicles passed by between 05:00 and 21:00 LT; the hourly traffic flows were then more than four times higher than during the nights (21:00-05:00). The traffic peak hours occurred regularly in the morning between 06:30 and 09:00 and in the afternoon between 15:30 to 18:30. There is little variation from this pattern across the individual weekdays, which indicates regular traffic and commuter patterns for the A100.

On Saturdays the average traffic volume was less than 140000 vehicles. The share of the lorry-like class fell to about $3.3 \%$. The peak levels occurred now in the early afternoon between 13:15 and 15:15. Traffic flows in the late 
Table 2. Traffic volume on the A100, Berlin. The values represent averages over ten weeks between 28 June and 5 September 2005.

\begin{tabular}{|c|c|c|c|c|c|c|c|c|}
\hline & & \multicolumn{3}{|c|}{ total vehicle number } & \multicolumn{3}{|c|}{ traffic flow in veh. $h^{-1}$} & \multirow{2}{*}{$\begin{array}{l}\text { lorry } \\
\text { share }\end{array}$} \\
\hline & & all vehicles & pass. car-like & lorry-like & all vehicles & pass. car-like & lorry-like & \\
\hline \multirow{3}{*}{ daytime (05:00-21:00) } & Mon-Fri & 161400 & 151200 & 10200 & 10090 & 9450 & 640 & $6.3 \%$ \\
\hline & Sat & 115600 & 111600 & 4000 & 7230 & 6980 & 250 & $3.5 \%$ \\
\hline & Sun & 103200 & 100600 & 2600 & 6450 & 6290 & 160 & $2.5 \%$ \\
\hline \multirow[t]{3}{*}{ nighttime (21:00-05:00) } & Mon-Fri & 19300 & 18400 & 900 & 2410 & 2300 & 110 & $4.7 \%$ \\
\hline & Sat & 22000 & 21400 & 600 & 2750 & 2680 & 80 & $2.7 \%$ \\
\hline & Sun & 21000 & 20500 & 500 & 2630 & 2560 & 60 & $2.4 \%$ \\
\hline \multirow[t]{3}{*}{$24 \mathrm{~h}(00: 00-24: 00)$} & Mon-Fri & 180700 & 169600 & 11100 & 7530 & 7070 & 460 & $6.1 \%$ \\
\hline & Sat & 137600 & 133000 & 4600 & 5730 & 5540 & 190 & $3.3 \%$ \\
\hline & Sun & 124200 & 121100 & 3100 & 5180 & 5050 & 130 & $2.5 \%$ \\
\hline
\end{tabular}

night/early morning hours were higher than on weekdays, indicating a higher share of leisure trips. On Sundays the traffic volume was about 125000 vehicles or $70 \%$ of the weekday traffic. The share of lorry-like vehicles decreased to $2.5 \%$. The traffic volume peaked between 13:10 and 15:40, and between 17:00 and 19:00 as well. Again, traffic flow at late nights/early mornings was higher than on weekdays.

Figure 3a shows the average diurnal traffic cycles: On weekdays the traffic flow sharply rises at around 06:00 to about 10000 veh. $\mathrm{h}^{-1}$, stays at about this level during the day and begins to decline from 18:30 onwards. There is no morning rush hour on Saturdays and Sundays because far less people travel to work and as the time patterns are more relaxed. The volume of lorry-like vehicles is much lower on weekends, and declining from Friday night to Saturday and rising again on Sunday evenings. This corresponds to usual working patterns while the early increase indicates the onset of long-distance and supply traffic.

As the mix between passenger cars and lorries changes over the day and between the weekdays, the average emission from traffic is anticipated to change as well. The ratio between the numbers of lorry-like and passenger car-like vehicles is shown in Fig. 3a. On weekdays the hourly share of lorry-like vehicles is relatively constant between $7 \%$ and 9\% from 06:00 and 16:00 but reaches a minimum between 20:00 and 23:00; the maximum share of lorry-like vehicles was $15 \%$, and occurred in the early morning hours (02:00 and 04:00): At this time passenger car-like vehicles are at an absolute minimum, while lorry-like traffic is rising. This phenomenon is of interest when co-analyzed later with the meteorological conditions prevailing in the early morning hours. On Saturdays the share of lorry-like vehicles is much lower than on weekdays, but also peaks in the early morning. On Sundays the share of lorry-like vehicles stays low throughout the day, and rises only slightly towards the night. This results from legal traffic restrictions, which prohibit lorry traffic on Sundays until 22:00 except for perishable goods.

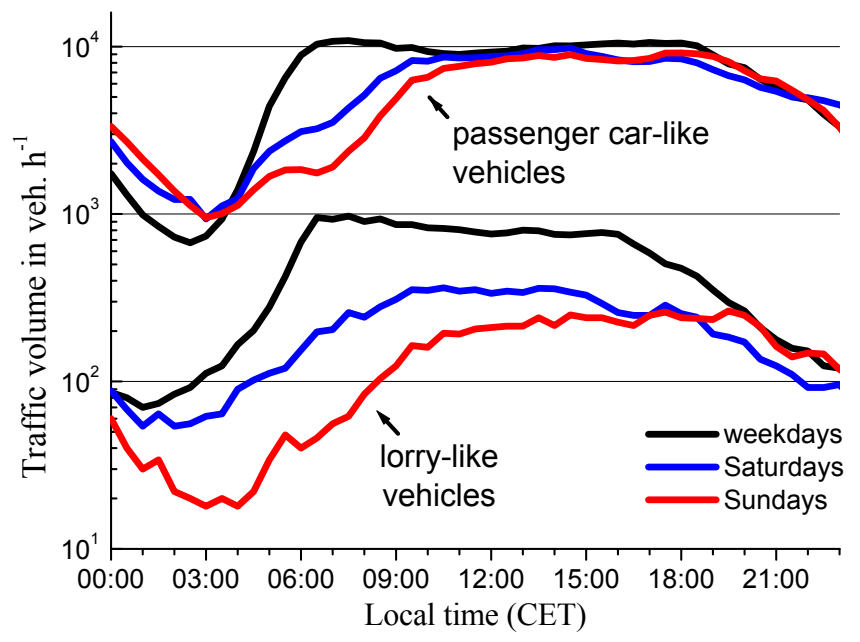

(a)

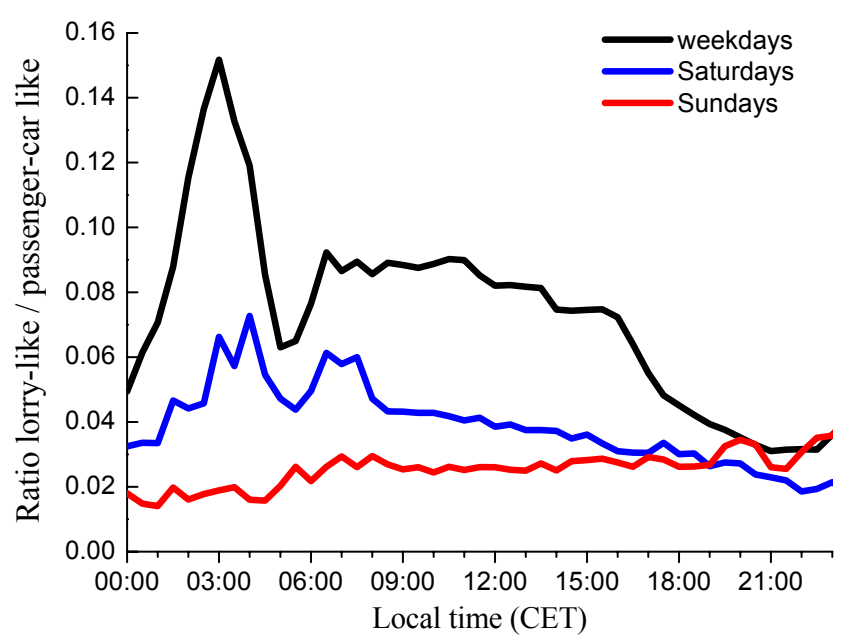

(b)

Fig. 3. Traffic parameters on the A100 motorway: (a) Diurnal cycle of traffic volume for passenger car-like and lorry-like vehicles. (b) the ratio between lorry-like and passenger car-like vehicles. 


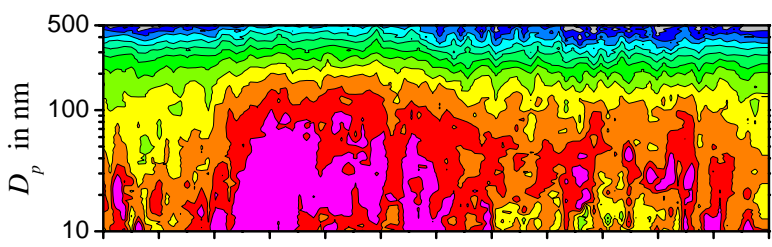

(a)

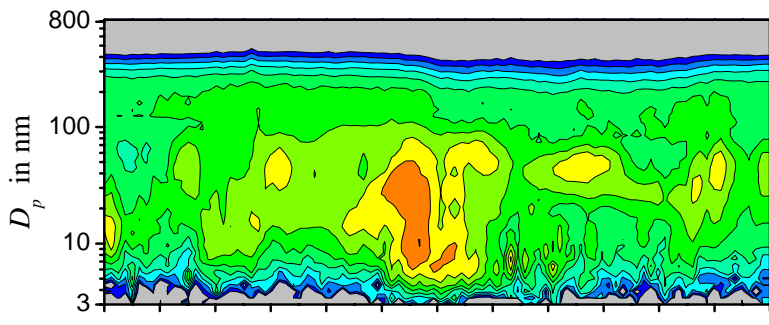

(b)

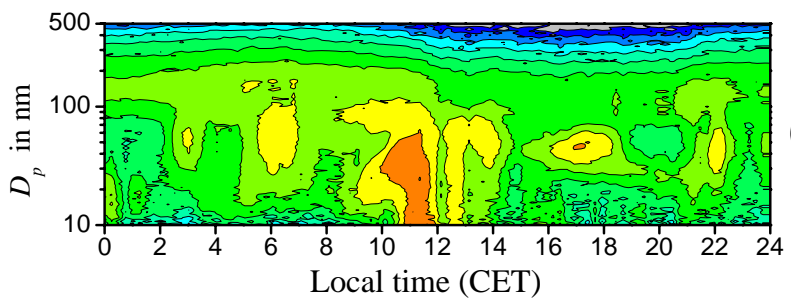

(c)

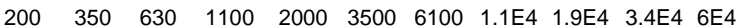

Fig. 4. Particle number size distributions $\left(\mathrm{d} N / \mathrm{d} \log \mathrm{D}_{p}\right.$ in $\left.\mathrm{cm}^{-3}\right)$ at the three urban measurement sites on 12 July 2005: (a) roadside, (b) background, (c) distant background.

A specialised follow-up campaign on Tuesday, 27 March 2007 focussed on the traffic entering and exiting at Spandauer Damm: On that day, about 1200 to 1500 vehicles left and entered the motorway on hourly average during daytime. This corresponds to about $12-15 \%$ of the vehicles on the motorway. The numbers of vehicles entering northbound and exiting southbound differed by a few 100 vehicles per hour. Hence, the traffic counts on the main motorway, performed north of this point, were adjusted by this difference: During daytime the hourly traffic volume was raised by about 300 vehicles, i.e. $3 \%$ of the total hourly traffic flow. Although no data is available for the nighttime, we expect only a minor bias on the final traffic counts.

Although the speed limit is $80 \mathrm{~km} \mathrm{~h}^{-1}$ on the section of motorway under study, the traffic density turns out to be the limiting factor for the vehicle speed. The measured driving speeds fluctuated diurnally between 75 and $90 \mathrm{~km} \mathrm{~h}^{-1}$, with higher speeds during nighttime when the traffic volume was lower. During the peak hours the traffic flow became occasionally instable, stop-and-go traffic occurred. This feature was, however, not systematic and therefore not visible in the average traffic flows.

\subsection{Particle concentrations and size distributions}

In the proximity of the Berlin urban motorway we found exceptionally high levels of ambient particle number con-

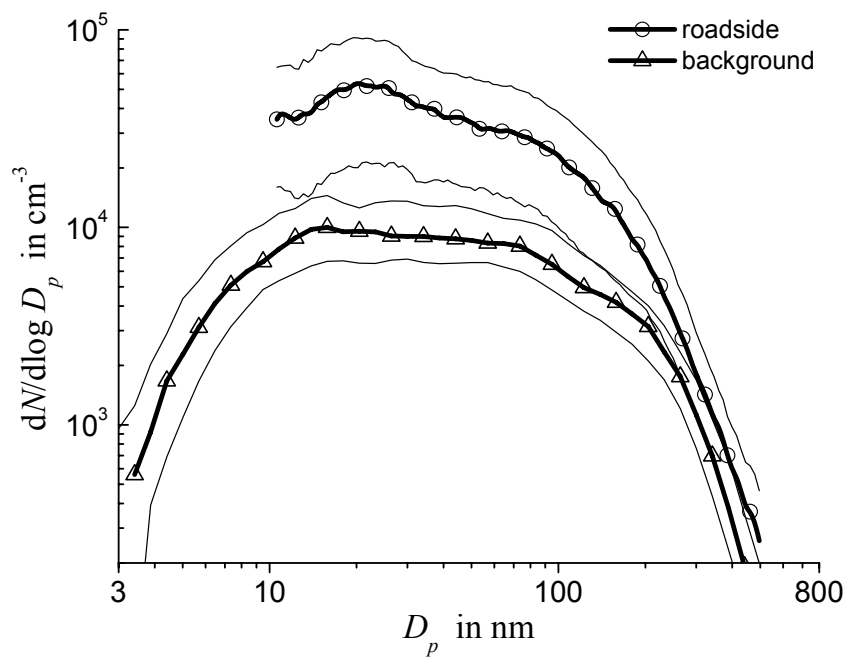

Fig. 5. Median particle number size distributions at roadside and in the urban background during peak traffic hours (07:00-09:00 local time). The thin lines correspond to the 25 th and 75 th percentile distributions.

centrations. At roadside, total particle number $\left(D_{p}>10 \mathrm{~nm}\right)$ exceeded $100000 \mathrm{~cm}^{-3}$ on many occasions. A maximum value of $168000 \mathrm{~cm}^{-3}$ was recorded during the morning peak traffic hours ("rush hours"), while the lowest concentration $1200 \mathrm{~cm}^{-3}$ occurred after midnight. The average total particle concentration for the whole measurement period was $28000 \mathrm{~cm}^{-3}$. The background site, located $80 \mathrm{~m}$ east of the motorway, featured considerably lower number concentration, $11000 \mathrm{~cm}^{-3}$ on average and varying between 1700 and $70000 \mathrm{~cm}^{-3}$. The distant background site, located $400 \mathrm{~m}$ downwind the traffic source, was characterised by the lowest total particle concentration of the three sites, $9000 \mathrm{~cm}^{-3}$ on the average, and varying in the range of $1800-60000 \mathrm{~cm}^{-3}$.

Figure 4 shows the diurnal evolution of the particle number size distribution at the three urban measurement sites on Tuesday, 12 July 2005 . One can clearly see the influence of traffic emissions at roadside, which features by far higher number concentrations than the background and distant background sites. The winds came from the north, thereby collecting pollution aerosol along the motorway. The concentrations at roadside show the greatest traffic-induced signal between $04: 00 \mathrm{~h}$, i.e. the onset of motorway traffic (Fig. 3), and 12:00 $\mathrm{h}$ on this day.

Although the two background sites are separated by a few major streets over a distance of about one $\mathrm{km}$ the evolution of their number size distributions in Fig. 4 appears amazingly similar. The coincidence of individual aerosol plumes detected around 03:00, 06:00, 11:00, 13:00, 17:00, and 22:00 h in Fig. 4b-c illustrates the high spatial homogeneity of particle size distributions in the urban background around the motorway. It is clear that these plumes do not originate from the motorway but from sources that far enough upwind to be visible in the measurements at both background sites. 


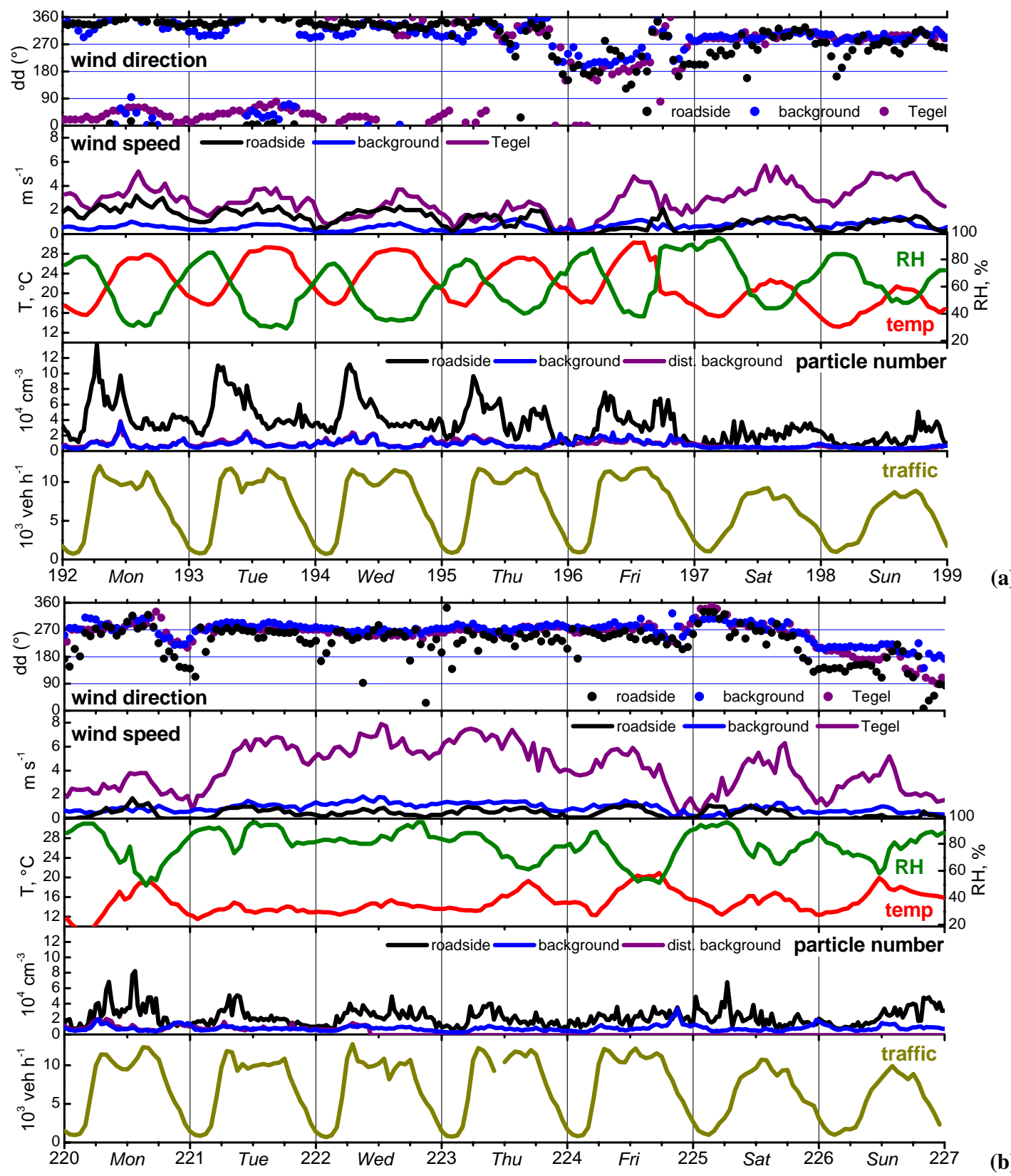

Fig. 6. Particles, traffic and meteorology near the A100 motorway during two weeks: (a) 11-17 July 2005, (b) 8-14 August 2005.

Table 3. Lognormal modal parameters of the number size distributions at the roadside and background sites. $D_{g 0}$ indicates mean geometric diameter, $N$ modal number concentration in $\mathrm{cm}^{-3}$, and $\sigma$ the geometric spread parameter.

\begin{tabular}{rrrrrrrrrr}
\hline & \multicolumn{3}{c}{ Young Aitken mode $(\sigma=1.70)$} & \multicolumn{2}{c}{ Aitken mode $(\sigma=1.58)$} & \multicolumn{3}{c}{ Accumulation mode $(\sigma=1.59)$} \\
\hline Perc. & $D_{g 0}$ in nm & $N$ (roads.) & $N$ (backg.) & $D_{g 0}$ in nm & $N$ (roads.) & $N$ (backg.) & $D_{g 0}$ in nm & $N$ (roads.) & $N($ backg.) \\
\hline 25 & 18 & 5400 & 2300 & 53 & 3800 & 1600 & 134 & 1800 \\
50 & 18 & 14000 & 4000 & 58 & 8000 & 2300 & 138 & 2900 & 1100 \\
75 & 18 & 32000 & 6700 & 65 & 15000 & 3500 & 147 & 3900 & 2000 \\
95 & 18 & 81000 & 14000 & 74 & 28000 & 6500 & 168 & 4400 & 3100 \\
99 & 18 & 140000 & 24000 & 81 & 39000 & 11000 & 208 & 3400 & 2600 \\
\hline
\end{tabular}




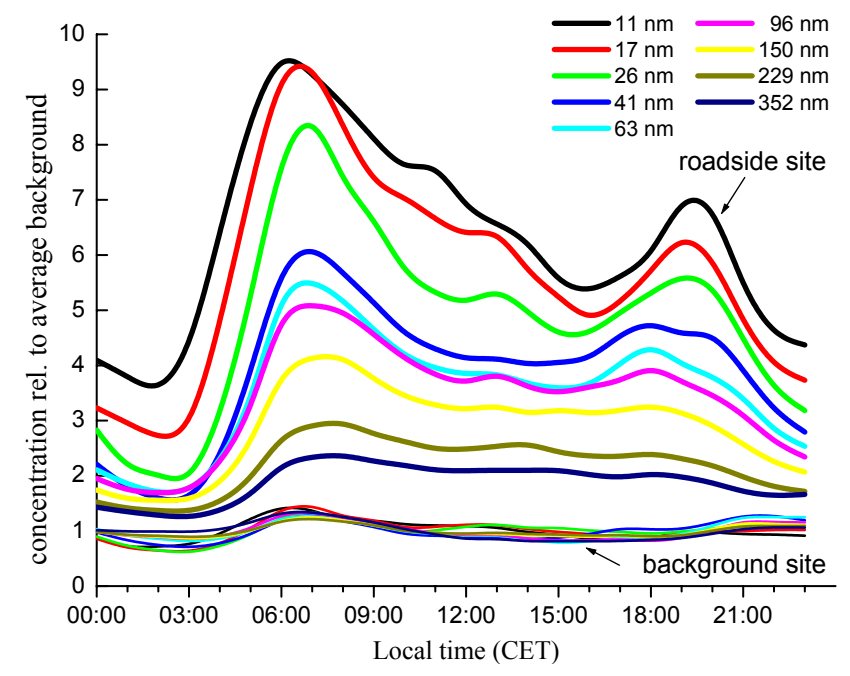

Fig. 7. The average diurnal cycle of particle number concentrations as a function of particle size on weekdays. The graph compares roadside and background, both normalised by the respective average level at the background site.

Figure 5 depicts average particle size distributions at the roadside and the background sites for the rush hour period 07:00-09:00 h. The influence of motorway emissions is most pronounced across the wide size interval between 10 and $200 \mathrm{~nm}$. To provide a more generally accessible version of the data, lognormal distributions were fitted to selected particle size distributions. Similar to earlier works (Morawska et al., 1999; Birmili et al., 2001; Hussein et al., 2005), three particle modes were found to be sufficient in parameterising the observations. The two modes with bigger diameters correspond to the Aitken and accumulation modes. The mode with smallest diameter was dubbed "young Aitken mode" and represents the mode nucleating from unburnt fuel compounds in the wake of the vehicles. Table 3 summarises the lognormal modal parameters of the size distributions modes at the roadside, background and distant background sites. The size distributions used were the 25th, 50th, 75th, 95th, and 99th percentile distributions simulating different degrees of pollution influence. To provide comparable modes, the spread parameter $\sigma$ was held fixed. Table 3 confirms the increasing impact of traffic emissions with decreasing particle size.

\subsection{One-week case studies}

To illustrate the influence of traffic and meteorological parameters on the measured concentrations, two one-week periods, each ranging from a Monday to a Sunday, were examined in detail. Week 1 covered the period between 11 and 17 July (Day of year 192-199), while Week 2 spanned from 8 to 14 August (Day 220-227). Figure 6 illustrates the observed variations of meteorological as well as particle and traffic parameters.
Week 1 was characterised by high air pressure and clear skies. Ambient temperature showed a clear diurnal variation and rose up to $30^{\circ} \mathrm{C}$ (Fig. 6a). From Monday to Thursday the Sun shone $12-15 \mathrm{~h}$ per day and also the weekend was sunny. The prevailing wind direction was north. The wind speed also exhibited a diurnal cycle with higher winds during the day. The week was intercepted by a weather change on Friday, when the wind briefly turned to westerly directions in association with a cold front and heavy rainfall towards Saturday. The traffic volume showed negligible variations from Monday to Thursday. According to the traffic speed measurements, there were only very few and short-lived traffic jams during this week. From Monday to Friday the roadside site featured morning peaks in total particle concentration of more than $100000 \mathrm{~cm}^{-3}$, but decreasing concentrations to about $40000 \mathrm{~cm}^{-3}$ in the afternoon under similar traffic volumes. A prime reason for the afternoon decline is the more intense vertical mixing of the atmosphere around and after mid-day. On the weekend, the overall concentrations were substantially lower due to smaller traffic volumes and wind blowing from the west. In summary, week 1 illustrates that the diurnal cycle of roadside particle concentrations can be very reproducible under the same meteorological conditions.

Week 2, in contrast, was characterised by low pressure influence and, for summer, quite low daily maximum temperatures $\left(15-20^{\circ} \mathrm{C}\right)$ with no clear diurnal cycle (Fig. 6b). The Sun shone only on Monday and Friday, with clouds prevailing during the rest of the week. The wind blew steadily from the west with relatively high wind speeds from Tuesday to Thursday. Occasionally, the traffic volume was lower than usual due to traffic jams with minimum driving speed of less than $40 \mathrm{~km} \mathrm{~h}^{-1}$ in the afternoons on Tuesday-Friday. During week 2 the particle number concentrations were generally low-level, seldom exceeding $50000 \mathrm{~cm}^{-3}$ at roadside. It appeared to us that the westerly wind placed the roadside site upwind of the motorway, and thus accounted for the low roadside concentrations. During a few periods of stagnant air (local wind speeds near zero), particle concentrations at the background site were also able to increase significantly, above $20000 \mathrm{~cm}^{-3}$. The case study of week 2 shows that under meteorological conditions favourable for dilution, ambient particle concentrations stayed low.

\subsection{Diurnal cycle}

The periodicity of the traffic source leads to a clear diurnal variation in particle concentrations: Fig. 7 presents average diurnal cycles for particle number concentrations on weekdays. The concentrations at each particle diameter were normalised by the average levels at the background site. A first feature is that the traffic influence increases with decreasing particle size. During the rush hour, the concentrations at roadside reach twice the background value for $D_{p}>300 \mathrm{~nm}$ but more than 9 times the background value for $D_{p}<20 \mathrm{~nm}$ (Fig. 7). At the background site, a weaker diurnal trend can 

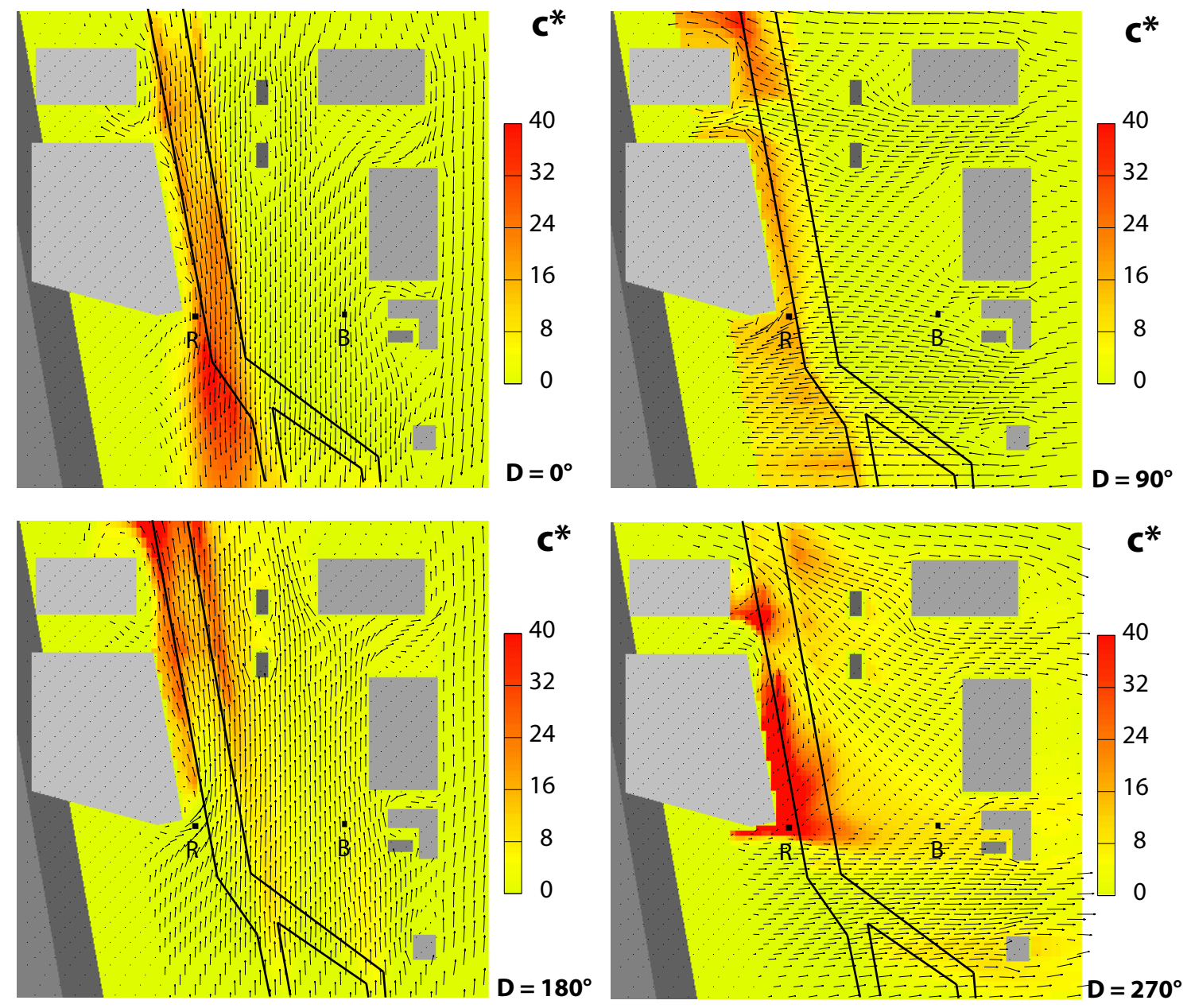

Fig. 8. Wind field and normalised concentrations in the layer of the height of the roadside site (R) for driving wind from north $\left(D=0^{\circ}\right)$, east $\left(D=90^{\circ}\right)$, south $\left(D=180^{\circ}\right)$, and west $\left(D=270^{\circ}\right)$.

be seen, in a similar fashion for all particle sizes. During the weekend (data not shown), the diurnal patterns are less pronounced as a result of the relaxed traffic pattern.

\section{Dispersion modelling results}

\subsection{3-D simulation results}

Figure 8 illustrates the simulated wind fields based on the technique presented in Sect. 3.1. Red colours indicate the concentrations of the traffic tracer and thus picture the dispersion of motorway emissions within the modelling domain. The layer shown corresponds to the height of the roadside measurement site, ca. $13 \mathrm{~m}$ above ground level and about $9 \mathrm{~m}$ above the motorway. Grid cells in this layer that are covered by buildings or the orographically varying surface appear in gray. A total of ten simulations, corresponding to ten wind directions was performed. Table 4 compiles these complete simulation results.
Under southerly and northerly wind directions $(D=0$ and $180^{\circ}$ ), the model predicts the highest tracer concentrations directly over, and adjacent to the motorway, which is straightforward from its north-south alignment. Under easterly winds $\left(90^{\circ}\right)$, areas to the west of the motorway are affected by the motorway plume. The most complicated situation occurs under westerly winds $\left(270^{\circ}\right)$ where both areas upstream and downstream of the motorway show high concentrations of traffic tracer. A vertical cross-section in east-west direction (not shown) reveals a vertical vortex behind the tallest building block, associated with small wind speeds and low exchange conditions.

A conclusion with respect to the roadside measurement site ("R" in Fig. 8) is that the traffic-derived concentrations there vary greatly with wind direction. The concentrations are predicted to be high under northerly winds, moderate under easterly winds, and low under southerly winds. Although the roadside site is located upstream of the motorway, the model predicts relatively large concentrations under westerly 
Table 4. Simulated wind direction, normalised wind speed $\left(u^{*}\right)$ and particle concentrations $\left(c^{*}\right.$ and $\left.c^{*} u^{*}\right)$ at the positions of the roadside and background measurement sites. The calculations refer to 10 discrete directions of the driving large scale wind $\left(U=10 \mathrm{~m} \mathrm{~s}{ }^{-1}\right)$ at $h=100 \mathrm{~m}$.

\begin{tabular}{|c|c|c|c|c|c|c|c|c|}
\hline \multirow{3}{*}{$\begin{array}{l}\text { large scale } \\
\text { wind dir. }\end{array}$} & \multicolumn{4}{|c|}{ roadside site "R" } & \multicolumn{4}{|c|}{ background site "B" } \\
\hline & \multicolumn{2}{|c|}{ simulated wind } & \multicolumn{2}{|c|}{ simulated concentrations } & \multicolumn{2}{|c|}{ simulated wind } & \multicolumn{2}{|c|}{ simulated concentrations } \\
\hline & wind dir. & $u^{*}$ & $c^{*}$ & $c^{*} u^{*}$ & wind dir. & $u^{*}$ & $c^{*}$ & $c^{*} u^{*}$ \\
\hline $0^{\circ}$ & $5^{\circ}$ & 0.37 & 18.2 & 6.7 & $0^{\circ}$ & 0.30 & 0 & 0 \\
\hline $45^{\circ}$ & $26^{\circ}$ & 0.52 & 32.6 & 16.9 & $30^{\circ}$ & 0.25 & 0 & 0 \\
\hline $90^{\circ}$ & $58^{\circ}$ & 0.39 & 18.9 & 7.4 & $96^{\circ}$ & 0.33 & 0 & 0 \\
\hline $135^{\circ}$ & $145^{\circ}$ & 0.22 & 21.3 & 4.7 & $110^{\circ}$ & 0.27 & 0 & 0 \\
\hline $180^{\circ}$ & $225^{\circ}$ & 0.55 & 0 & 0 & $174^{\circ}$ & 0.33 & 5.0 & 1.7 \\
\hline $225^{\circ}$ & $258^{\circ}$ & 0.50 & 0.13 & 0.06 & $219^{\circ}$ & 0.28 & 6.5 & 1.8 \\
\hline $270^{\circ}$ & $36^{\circ}$ & 0.06 & 65.7 & 3.9 & $264^{\circ}$ & 0.46 & 8.4 & 3.9 \\
\hline $292^{\circ}$ & $55^{\circ}$ & 0.10 & 59.4 & 5.9 & $324^{\circ}$ & 0.30 & 3.4 & 1.0 \\
\hline $315^{\circ}$ & $20^{\circ}$ & 0.15 & 44.9 & 6.7 & $313^{\circ}$ & 0.34 & 4.0 & 1.4 \\
\hline $338^{\circ}$ & $5^{\circ}$ & 0.26 & 8.2 & 2.1 & $343^{\circ}$ & 0.31 & 0.28 & 0.09 \\
\hline
\end{tabular}

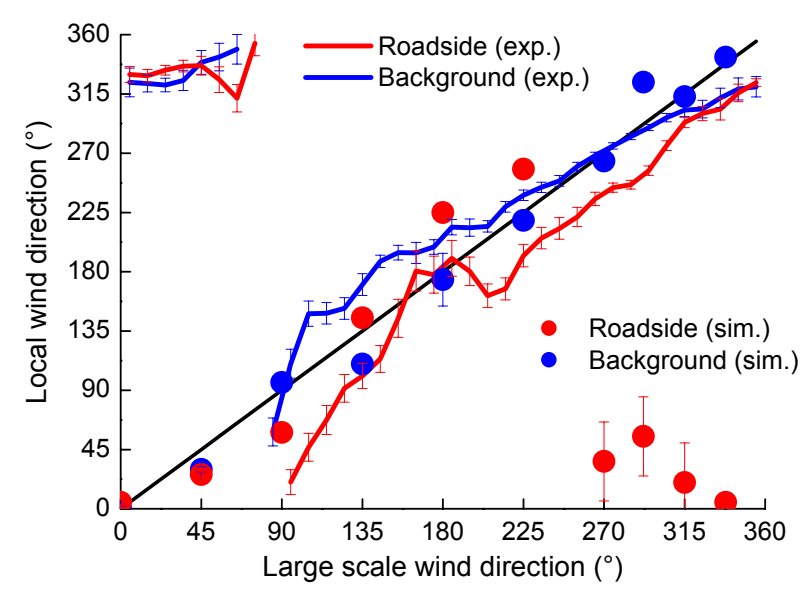

(a)

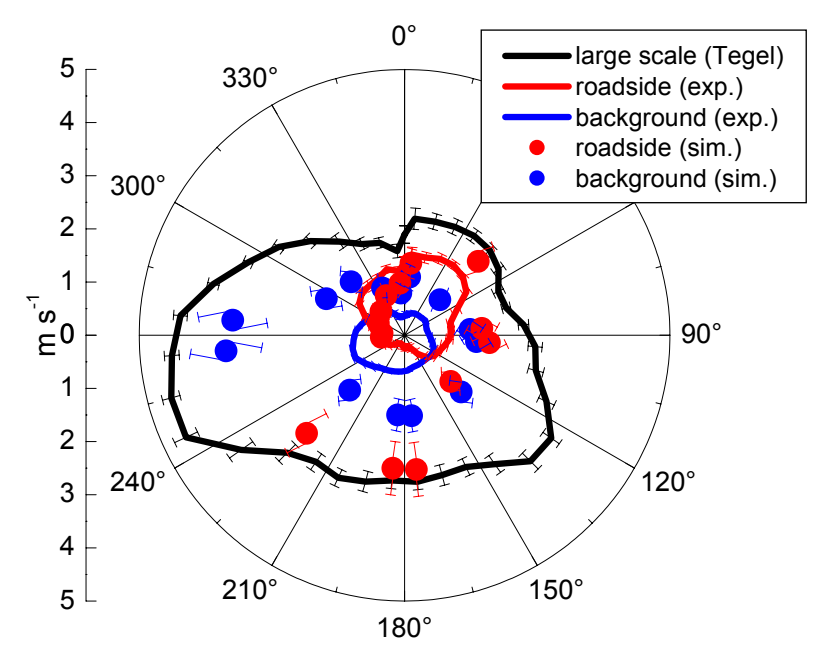

(b)

Fig. 9. Comparison of simulated and experimental winds as a function on the large scale wind direction: (a) wind direction, (b) wind speed. winds because of the aforementioned leeward vertical and horizontal vortices above the motorway (Fig. 8, 270 $)$. Minor changes in the position of the receptor point led to large variations in the predicted concentrations, and it is our impression that under westerly winds the roadside site $(\mathrm{R})$ is located critically near this horizontal vortex with its associated high concentration gradients.

An overall look at the tracer concentrations of the background measurement site ("B" in Fig. 8) showed only marginal contributions from the motorway except under westerly winds $\left(270^{\circ}\right)$, which place this site downwind of the motorway. Simulations similar to those in Fig. 8 were performed for the dispersal of the Spandauer Damm street traffic emissions (Fig. 1). These simulations suggested only a marginal influence of the Spandauer Damm street emissions on the concentrations at the roadside and background sites compared to the A100 motorway.

\subsection{Validation of wind parameters}

The local wind speed measurements were used to validate the performance of our 3-D dispersion model. Figure 9a compares the simulated and experimental wind directions for the roadside and background sites. All wind directions are plotted against the large scale wind direction (Tegel airport), which is driving the simulation. A main result is that the wind direction at the background site is reproduced relatively accurately by the model. This is not surprising given the relatively unobstructed position of that site ("B" in Fig. 8).

At the roadside site, an agreement between simulations and experiment can be found for the majority of wind directions, with the notable exception of westerly and northwesterly winds (270-315 ${ }^{\circ}$ in Fig. 9). While the simulation predicts the roadside site to lie in the vortex counterflow behind the large building block (Fig. 8) the experimental values plead for a close coupling of the large-scale and local winds. 
Table 5. Particle number emission factors (particle size range: 10$500 \mathrm{~nm}$ ) for the A100 motorway using the three calculation approaches in $10^{14} \mathrm{veh}^{-1} \mathrm{~km}^{-1}$.

\begin{tabular}{crrr}
\hline \multicolumn{4}{c}{$E$ based on $c$ (roadside)- $c$ (background) } \\
\hline period (LT) & Eq. (6) & Eq. (8) & Eq. (9) \\
\hline $01: 00-07: 00$ & $2.81(0.71)$ & $2.83(0.22)$ & $2.16(0.23)$ \\
$07: 00-14: 00$ & $1.85(0.21)$ & $2.49(0.25)$ & $1.85(0.37)$ \\
$14: 00-21: 00$ & $1.18(0.14)$ & $1.48(0.16)$ & $1.17(0.14)$ \\
\hline
\end{tabular}

This deviation between simulations and experiment is likely a result of the complex local topography around the roadside site, which can only be reproduced in the model with a high degree of simplification. It is an intriguing feature of the model simulation that it ascribes a higher degree of uncertainty to the simulated wind directions from the westerly sector; in fact, the model recognizes that this flow situation leads to unstable results for the given configuration of westerly winds at the roadside site.

The comparison of simulated and experimental wind speeds in Fig. 9b yields similar conclusions. The ratio between modelled and measured wind speed was between 2.1 and 4.2 for the background site: The model systematically overestimates the real wind speeds. Here, our conclusion is that the generally assumed roughness length of $0.1 \mathrm{~m}$ might not be appropriate for the surroundings of the background site. Although the wind sensor was located $6 \mathrm{~m}$ above the ground, adjacent trees existed around the site - not represented by the model, which likely reduced the overall levels of the local wind speeds.

The results were more diverse at the roadside site: While a fair agreement between modeled and measured wind speed (ratio between 0.5 and 1.0) was achieved for northerly and easterly wind directions $\left(338-330^{\circ} ; 0-145^{\circ}\right)$, the comparison is more erratic for southerly and westerly winds. Consequently, all emission factors calculated below were aggregated for the wind sector $330-150^{\circ}$ only.

\section{Experimental vehicle emission factors}

\subsection{Fleet emissions on weekdays}

Figure 10 shows average diurnal cycles of the particle number emission factor using the three different approaches introduced in Sect. 3.2. The values are generally based on the concentration difference between the roadside and background site, respectively. (Tests were carried out using background values only, thereby taking a floating $24 \mathrm{~h}$-minimum value as a background measure. These showed qualitatively similar results but are not displayed here due to their much greater uncertainty.) In Fig. 10 particle number emission fac-

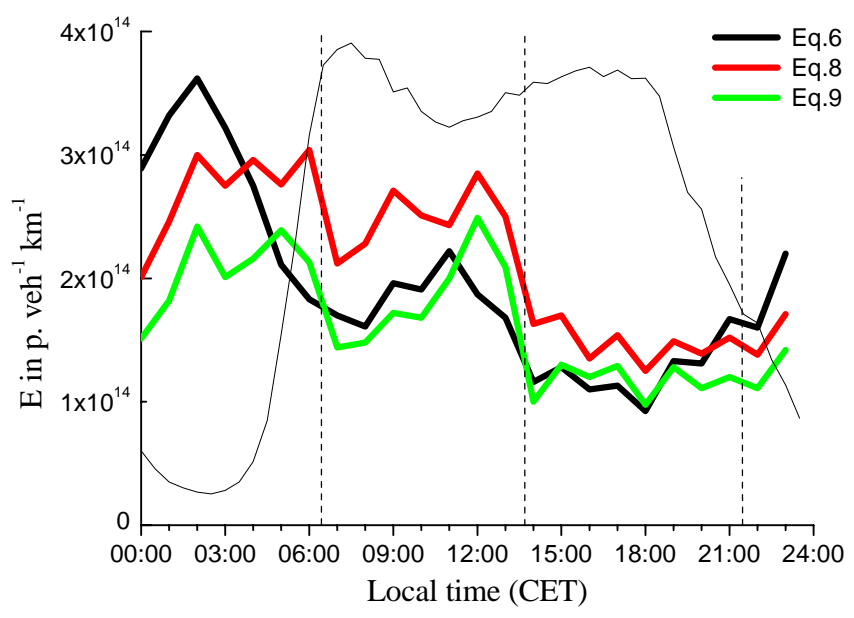

Fig. 10. Diurnal cycles of the fleet emission factor based on roadside minus background measurements using the three different calculation approaches. Vertical lines delimit the time periods evaluated in Sect. 6.1. The total traffic volume (without units) appears as a thin line.

tors $E$ range between 1 and $4 \cdot 10^{14} \mathrm{veh}^{-1} \mathrm{~km}^{-1}$ (wind direction $330-150^{\circ}$ only) depending on the time of day and the calculation approach used. The values derived from Eq. (6) - based on a coupling of the model to the large-scale wind, are comparable to those from Eq. (9), which are based on a coupling to the local wind. Equation (8) tends to produce the highest emission factors. Table 5 compiles the particle number emission factors for weekdays.

All approaches in Fig. 10 share three visible stages in the diurnal cycle: high values at night (21:00-06:00), medium values during mid-day 07:00-13:00), and lower values in the afternoon (14:00-21:00). Several possible explanations for these stages are outlined. First, the emission factor is expected to depend on the fleet composition, which varies throughout the day (Fig. 3b). On weekdays, the ratio between lorry-like and passenger car-like vehicles reaches a maximum of $15 \%$ at $03: 00 \mathrm{~h}$, which coincides with the maximum in $E$ around that time (Fig. 10). However, the overall traffic volumes and consequently the pollutant concentration are also the lowest during the night. When small values of $\bar{c}$ and $M$ are divided in Eqs. (6), (8) and (9), the result will accordingly be more uncertain. Third, rolling traffic causes a significant portion of air turbulence (e.g., Vachon et al., 2002). This is currently not accounted for in our dispersion model but expected to correlate with traffic volume.

\subsection{Effects of solar radiation}

The drop in the emission factor that occurred between 12:00 and 14:00 in Fig. 10 was scrutinised with respect to the possible influence of solar radiation. A data set of twenty-five weekdays, where the wind direction was within the sector $330-150^{\circ}$ were split into two subgroups, "sunny days" and 

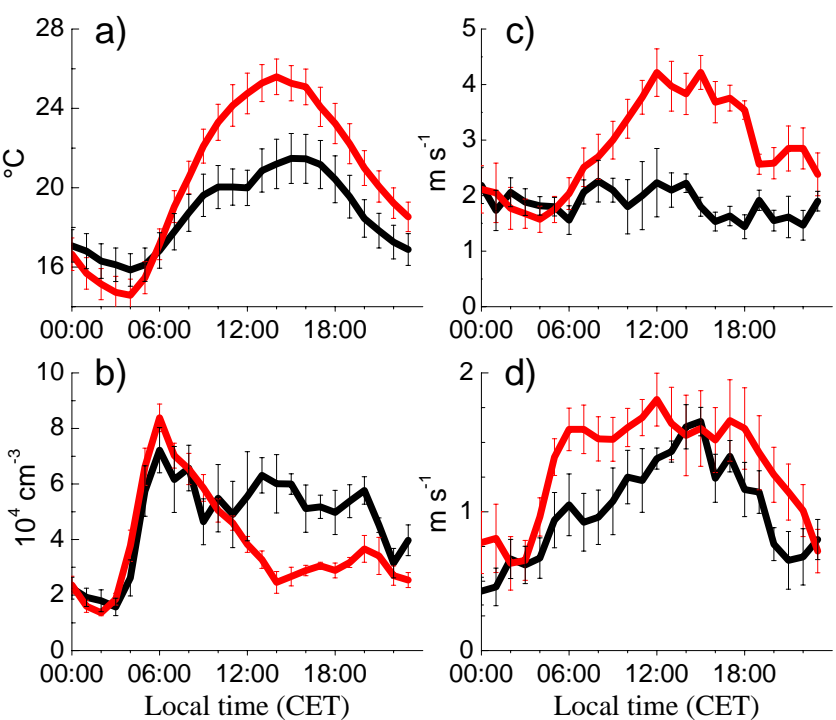

Fig. 11. Effects of solar radiation (red - sunny days, black - cloudy days): (a) ambient temperature (Tegel), (b) $\bar{c}$ (roadside - background), (c) wind speed (Tegel), (d) wind speed (roadside site).

"cloudy days" on the basis of the daily sunshine duration. Sunny days included 13 days with an average sunshine duration of $12.4 \mathrm{~h}$ (range: 10-15 h), whereas cloudy days involved 12 days with an average sunshine duration of $4.5 \mathrm{~h}$ (range: 0-9h). Figure 11a-d shows the diurnal effects of temperature, particle number concentration and wind speed.

The most significant feature is the drop in ambient number concentration $\bar{c}$ (roadside - background) after 12:00 on sunny days (Fig. 11b): On sunny days the value of $\bar{c}$ at 14:00 is only $40 \%$ of the corresponding value on cloudy days while before 12:00 the values are nearly identical. Traffic is not responsible for this drop, since it is was essentially the same on all weekdays. The horizontal wind speeds were higher on sunny days compared to cloudy days (Figs. 11c-d). However, wind speed-related volume dilution effect of the motorway aerosol is already accounted for in the calculation of $E$ in Eqs. (6), (8) and (9). In addition, the most relevant changes in the diurnal cycle of the wind speed take place before 12:00, i.e. their changes cannot be the cause of the drop in $E$ in Fig. 10.

As a consequence, we raise the hypothesis that thermal instabilities may be responsible for the drop in $\bar{c}$, and subsequently $E$. We see the connection to solar radiation (Fig. 11b) as a hint towards thermally-driven effects in the shape of enhanced vertical dilution. For sunny days, the assumption of a neutrally stable temperature profile in our model simulation might therefore not be appropriate. As a result, we consider the emission factors determined for the morning period (07:00-13:00; cf. Table 5) to be more reliable than those in the afternoon, where the model might show deficiencies in reproducing the real atmospheric effects.

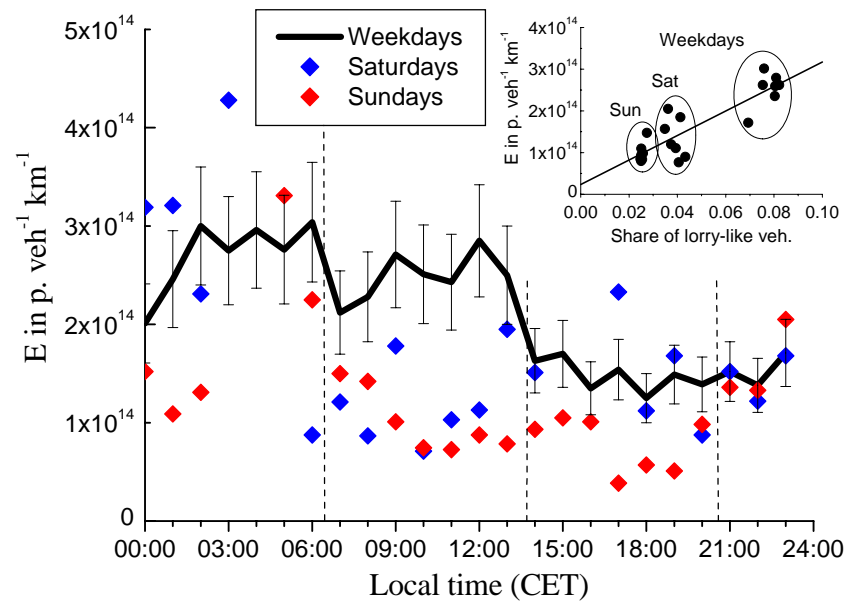

Fig. 12. Diurnal profiles of the emission factor $E$ at the roadside site for different times of the week using Eq. (8). Dashed lines delimit the range of reliable data. Inset: Correlation analysis for $E$ as a function of the relative share of lorry-like vehicles in the fleet.

\subsection{Weekend effects and lorry/passenger car split}

The diurnal cycle of the motorway emission factor was also calculated for weekends in order to assess the possible effects of a changing traffic composition. Figure 12 compares the diurnal cycles of $E$ on weekdays, Saturdays and Sundays based on Eq. (8). It can be seen that throughout the day, the weekend values of $E$ are substantially lower than on weekdays. This difference is obviously a result of the different share in lorry-like vehicles (Sect. 4.1). We evaluated this difference with the goal of estimating the relative contributions of lorry-like and passenger car-like vehicles to the total emission factor $E_{\text {total }}$. Assuming that $E_{\text {total }}$ can be described as a superposition of the factors of lorry-like $\left(E_{l}\right)$ and passenger car-like $\left(E_{p}\right)$ vehicles weighted after their relative shares $n_{l}$ and $n_{p}$ of the traffic volume and using $n_{p}=1-n_{l}$ we obtain

$E_{\text {total }}=\left(E_{l}-E_{p}\right) \cdot n_{l}+E_{p}$.

Following this equation $E_{\text {total }}$ is plotted against $n_{l}$ in Fig. 12 (inset) for data points ranging between 07:00 and 14:00. The slope of the fitted line is interpreted as $E_{l}-E_{p}$, while its y-intercept corresponds to $E_{p}$. Based on the time window 07:00-14:00 particle number emission factors of $29.6( \pm 3.5)$ and $0.24( \pm 0.15) \cdot 10^{14} \mathrm{veh}^{-1} \mathrm{~km}^{-1}$ were determined for lorry-like and passenger car-like vehicles, respectively. It is worth to note that $E_{l}$ could be derived with greater confidence than $E_{p}$ because the latter depended more sensitively on the propagation of experimental noise in Eq. (10). A further implication of the results is that on the Berlin urban motorway, lorry-like vehicles emit $123( \pm 28)$ times more particle number than passenger car-like vehicles, or that lorry-like vehicles account for $83 \%$ of day-time particulate number emissions on Saturdays and $91 \%$ on weekdays. 
We acknowledge that our results might be biased by the driving behaviour. On weekends, the traffic was always flowing at an average speed around $80 \mathrm{~km} \mathrm{~h}^{-1}$. During weekdays, limited periods of traffic congestion could occasionally be observed (less than $2 \mathrm{~h}$ per day), which led to average speeds as low as $50-60 \mathrm{~km} \mathrm{~h}^{-1}$. Although their effect on the calculated emission factors are hard to quantify, it is assumed that slower speeds will increase the experimental emission factor as a result of the vehicles' longer residence within the surroundings of the measurement site. Consequently, the emission factors for lorry-like vehicles have to be regarded as an upper estimate, and those for passenger car-like vehicles as a lower estimate.

\subsection{Emission factor size distributions}

The data was also used to determine size distributions of the emission factor. The necessary conditions used for determining representative values were, again, wind from the sector $330-150^{\circ}$ (roadside site downstream the motorway), a sufficient wind speed (Tegel wind speed $>2 \mathrm{~m} \mathrm{~s}^{-1}$ ), and the time window 07:00-16:00 (sufficient traffic volume). Figure 13 depicts the size distribution of $E$ obtained under these conditions. Due to the apparent bimodality of the distributions, two lognormal modes with geometric mean diameters of 17 and $71 \mathrm{~nm}$ were fitted. These modes are associated with the nucleation and soot modes commonly seen in tailpipe emissions (Kittelson, 1998), with the nucleation mode being generated in the free atmosphere downwind of the tailpipe.

\section{Discussion}

Vehicular emission factors were determined by quantifying the 3-D micro-meteorological dilution between the motorway as a source and a roadside receptor point. While this is similar to the practice of Gaussian plume models or street canyon dispersion models, the method is more different from the evaluation of the dilution in tunnel measurements or a calculation of emission factors by relating particle to gaseous tracer concentrations. A useful byproduct of our method is that, like every dispersion model, the 3-D simulation pictures the impact of traffic emissions in the surroundings of the motorway (Sect. 5.1). Concentration maps like Fig. 8 can be useful for the assessment of particle exposure in the residential areas near the motorway.

A sensitive issue for the quantification of the emission factor has been the choice of the experimental wind speeds that drive the flow model (Sect. 3.2). Three options were pursued, using the large-scale wind (Tegel airport; Eq. 6), the local wind at the receptor sites (Eq. 9), and a refined version of the first option, eliminating possible wind-directional bias due to inhomogeneous terrain (Eq. 8). When using the large-scale wind, the accuracy of the calculation is limited by the ability of the flow model to describe the microscale airflow between

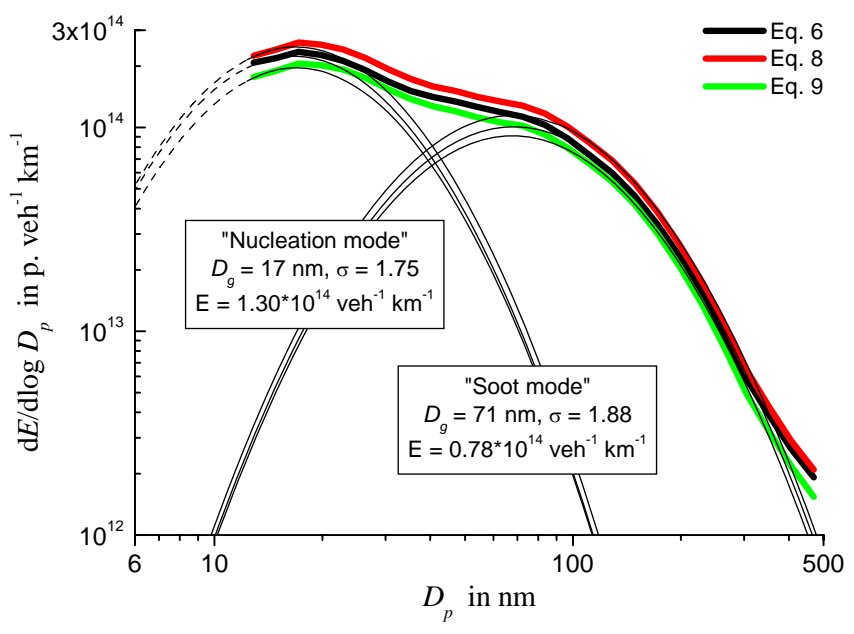

Fig. 13. Size distribution $\mathrm{d} E / \operatorname{d} \log D_{p}$ of the number emission factor using the three calculation approaches. Two lognormal modes were fitted, with their lognormal parameters indicated for Eq. (8). $E$ refers to the size range $D_{p}>10 \mathrm{~nm}$ covered by experimental data only.

the source and the receptor points, though the derived values also rely on the correct choice of roughness length when generating the large scale wind speed $(h=100 \mathrm{~m})$ from the near-surface measurements at Tegel $(h=10 \mathrm{~m})$.

The use of local winds to drive the flow model avoids several of these uncertainties but relies, on the other hand, on the model's ability to simulate the local flows near the surface. The simulations were considered satisfactory for the surroundings of the roadside site and the wind sector 330$150^{\circ}$ (i.e. downwind the motorway), but unsatisfactory for the wind speed at the background site albeit the wind direction could be simulated well there (Sect. 5.2). Our impression was that the divergence between the modelled and measured wind speeds near the latter site was caused by sub-scale roughness elements, which were not considered explicitly in the model. Overall, the three approaches produced comparable results for the roadside site (Fig. 10a). For the aggregation of the final fleet emission factors we selected data calculated by Eq. (8), and based on subtracting background from roadside concentrations.

Another issue has been the assumption of the emitted particles being inert during the transport. Aerosol simulations (Zhang et al., 2004) have suggested that particle growth and shrinkage, as well as changes in chemical composition occur downwind of traffic sources as a result of the rapid dilution. Calculations on the life-time of $18 \mathrm{~nm}$-particles (see Appendix) suggest that coagulation is not critical in reducing particle number concentration over the scale of minutes, once the particles have left the envelope of the A100 motorway. Our tentative assumption here is that most of the "tailpipe-to-ambient" dilution process has passed once the particles are detected at the roadside site. Further changes 


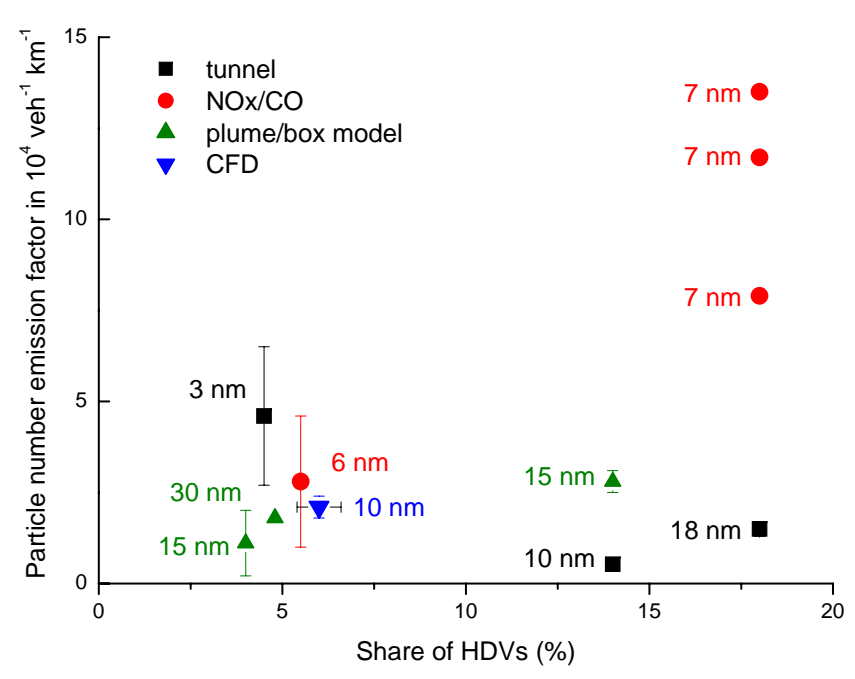

Fig. 14. Compilation of fleet emission factors of particle number as a function of the relative share of HDVs (studies since 2002). Indicated is the lower cut-off diameter of the particle number concentration measurement.

in particle number downwind due to aerosol dynamics are expected to be minor, so that the emission factors are considered representative for the flux of aerosol particles exiting through the envelope of the motorway at a distance of $6 \mathrm{~m}$ off the kerbside.

What vehicular fleet are the emission factors derived in this paper representative for? (HBEFA, 2004) report a $26 \%$ share of diesel vehicles among passenger cars in Germany in 2004. A field study in the surroundings of Berlin determined a somewhat lower fraction of $20 \%$ (LUA, 2006). (For vans and lorries the shares of diesel-driven vehicles were $86 \%$ and $100 \%$, respectively HBEFA, 2004). For the A100 motorway in 2005, we assume that the share of diesel vehicles among passenger cars was between the reported values of 20 and $26 \%$. Currently, the number of diesel vehicles among newly licensed cars is about 50\% in Germany and hence, the share of diesel vehicles in the fleet is constantly mounting. However, the fitting of diesel cars and HDVs with particulate filters is underway and expected to reduce particulate mass but also number emissions (Ban-Weiss et al., 2008). Therefore, our values need to regarded as specifically representative of the state in 2005.

It is also worth to recall that our measurements took place during summer (average temperature $18^{\circ} \mathrm{C}$, relative humidity $50-90 \%$, average cloud cover $50 \%$ ), and that the emission factors derived are representative for such meteorological conditions only. We are aware that for thermodynamic reasons the particulate number emission factor may increase with decreasing temperature, as indicated by other works (Olivares et al., 2007; Jamriska et al., 2008).

Table 6 compiles numerous works in which particulate emission factors were determined from stationary near- road measurements, particularly focussing on roads where the traffic is free flowing and travelling speeds are at $80 \mathrm{~km}^{-1} \mathrm{~h}^{-1}$ and higher. More comprehensive surveys of traffic-derived emission factors have been provided elsewhere (Jones and Harrison, 2006; Beddows and Harrison, 2008).

The number emission factors compiled in Table 6 vary by roughly one order of magnitude within each category, between 0.5 and $14 \cdot 10^{14} \mathrm{veh}^{-1} \mathrm{~km}^{-1}$ for mixed fleets, $7-70 \cdot 10^{14} \mathrm{veh}^{-1} \mathrm{~km}^{-1}$ for HDVs, and $0.2-$ $7 \cdot 10^{14} \mathrm{veh}^{-1} \mathrm{~km}^{-1}$ for LDVs. While these differences between different experiments might be real, owing to different fleet compositions (i.e. engine types, fuel types, vehicle age) and driving behaviour, they could also be artificial due to the non-equivalence of the methodologies, notably considering the distance of the sampling point from the traffic source, different gaseous traffic tracers used (or not), or different dispersion modelling approaches. Lastly, particles were detected using different measurement equipment. When dealing with particle number measurements, especially the lower cut-off size of the instrumentation is a relevant issue.

Figure 14 visualises the most significant overall trend detectable in Table 6, the trend between the mixed fleet emission factor and the fraction of HDVs. This trend is plausible in view of the dominating role of HDV emissions. Furthermore, it appears that higher experimental cut-off sizes yield lower emission factors - not surprising in view of the substantial particle concentrations emitted in the diameter range between 3 and $30 \mathrm{~nm}$, where the experimental cut-off diameters of the particle mobility spectrometers and/or particle counters can be found.

The span of emission factors compiled in Table 6 appears explainable by deviations in the structure of the vehicle fleets, different seasons during which measurements took place as well as systematic differences between the different calculation methods. European vehicle fleets usually contain a substantial fraction of diesel-driven LDVs while in Australia, their number is negligible (Morawska et al., 2005). Further non-comparability may result from differences in the methods of classifying vehicles into HDVs, LDVs, and an eventual intermediate class (transport vehicles, "vans"), which is usually accomplished by vehicle length in optical detection systems.

\section{Conclusions}

Measurements of atmospheric particle number size distributions in the vicinity of the A100 urban motorway in Berlin, Germany, yielded average total particle concentrations of $28000 \mathrm{~cm}^{-3}\left(1200-168000 \mathrm{~cm}^{-3}\right)$ at roadside $(6 \mathrm{~m}$ off the kerbside), and around 11000 and $9000 \mathrm{~cm}^{-3}$ at two distances of 80 and $400 \mathrm{~m}$ downwind, respectively. The measured particle numbers depended highly on the traffic volume, but also 
Table 6. Comparison of literature emission factors. Emphasis is directed towards roads with free-flowing traffic and travelling speeds of $80 \mathrm{~km} \mathrm{~h}^{-1}$ and greater. Uncertainties are indicated in brackets. The lorry-like vehicles characterised in our work were compared to heavyduty vehicles (HDV). Results for passenger-car like vehicles, which include light-duty vehicles, were compared with published emission factors on light duty vehicles (LDV). Our work used computational fluid dynamics (CFD) to estimate the dilution of traffic exhaust.

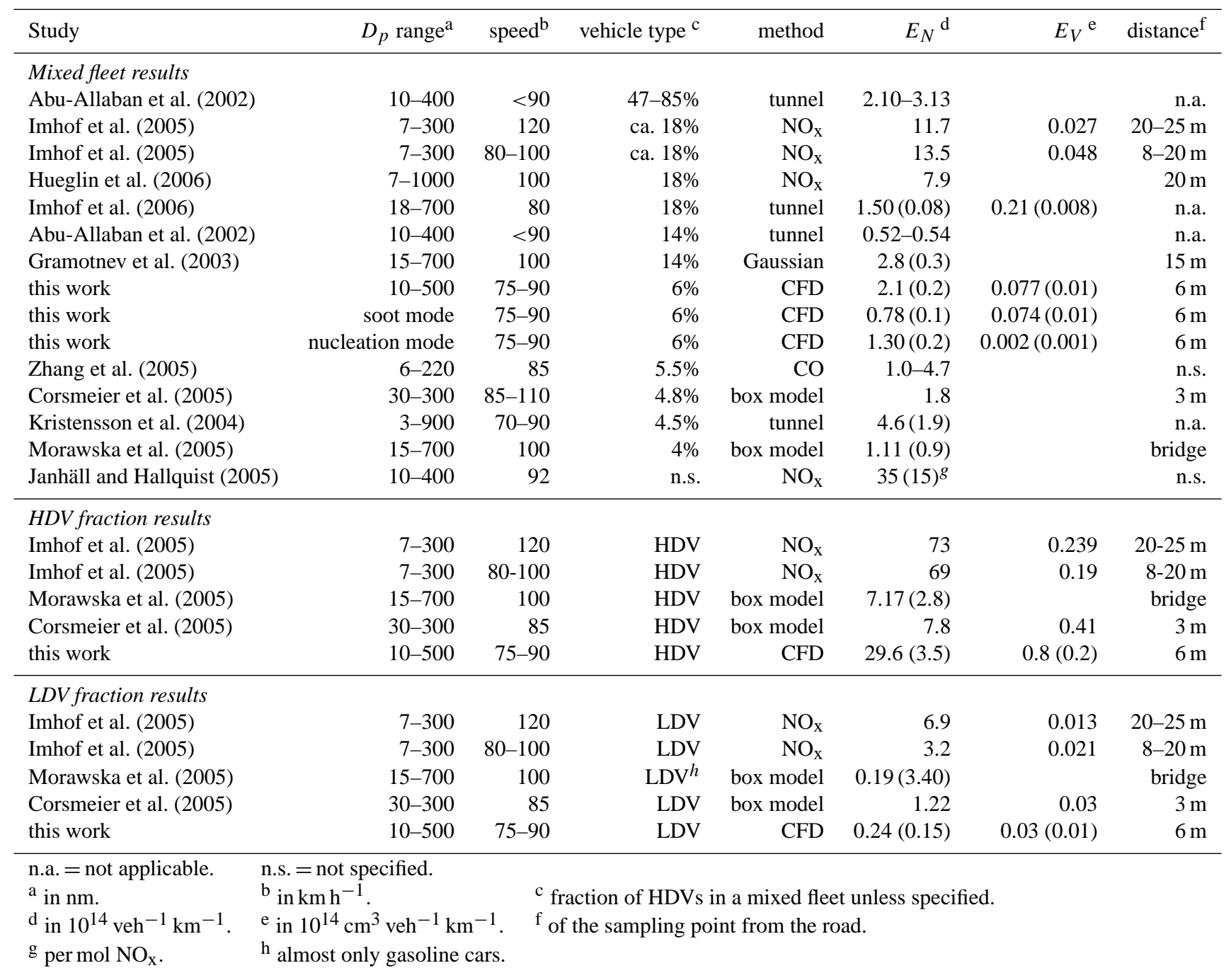

sensitively on the meteorological conditions including wind speed, wind direction, and solar radiation. While the general features of the observations agree with the findings of many former studies, it is the large volume of traffic (180000 vehicles on a weekday at a share of $6 \%$ lorry-like vehicles) in a densely populated area which make the location of the A100 a relevant showcase to study the dispersion of traffic-related particles in a complex urban landscape.

An obstacle resolving dispersion model (ASAM) was used to simulate the 3-D flow field as well as the transport and dilution of a traffic-emitted tracer in an area with $500 \mathrm{~m}$ horizontal box size. Great care was taken with the accurate spatial representation of the obstacles (horizontal resolution $5 \mathrm{~m}$ ) in the area and the motorway as a traffic source. The simulation was able to explain the overall spatio-temporal trend of the measured particle size distributions with a notable exception of westerly flow, where the situation of real obstacles was the most complicated. By a validation of the model with the experimentally measured local winds, a sub-set of the data (wind sector 330-150 ) could be identified when the roadside receptor point was in a defined situation downwind of the motorway as the particle source.

Using the method of inverse modelling, vehicle emission factors were derived. The average number emission factor per vehicle was $2.1( \pm 0.2) \cdot 10^{14} \mathrm{~km}^{-1}$ for the particle size range $10-500 \mathrm{~nm}$. A corresponding factor of $0.077( \pm 0.01) \cdot 10^{14} \mathrm{~cm}^{3} \mathrm{~km}^{-1}$ could be determined for the particulate volume. After fitting two lognormal modes to the emission factor number size distribution, values of 0.78 $( \pm 0.1)$ and $1.30( \pm 0.2) \cdot 10^{14} \mathrm{~km}^{-1}$ were obtained for the 
soot mode and the nucleation mode, respectively. By combining weekday and weekend observations, we were able to delineate the contributions caused by lorry-like and passenger car-like vehicles, suggesting that that lorry-like vehicles emit $123( \pm 28)$ times more particulate number than passenger car-like vehicles, and that lorry-like vehicles account for about $91 \%$ of particulate number emissions on weekdays.

An issue relevant to the quantification of the emission factor was the choice of the experimental wind speeds that served to drive the flow model. Three options were pursued, using either a large-scale wind, a local wind at the receptor site, or an alternative version of the first approach eliminating possible wind-directional bias. Our general conclusion is that the three approaches produce comparable results when applied to a traffic-induced contribution derived by subtracting background site measurements from roadside measurements. For the afternoon (14:00-21:00), our method yielded lower emission factors than for morning hours (07:00-13:00). A sensitivity analysis with respect to sunshine duration suggested that the afternoon values might be degraded by solar radiation-induced thermal instabilities that are not accounted for in the dispersion model. Our recommendation has therefore been to use the emission factors determined for the morning hours (07:00-13:00), where thermal effects play a lesser role.

It has been an unusual approach to determine emission factors by taking into account meteorological dilution calculated from an explicit 3-D flow model. Previous works have often relied on parameterised box or plume models, the consideration of air dilution in tunnels, or a coupling to gaseous tracers $\left(\mathrm{CO}, \mathrm{NO}_{\mathrm{x}}\right)$. A certain advantage of our method is that the 3-D simulation can quantify the effects of additional minor roadways in the surroundings, and picture the spatial impact of traffic emissions in the entire urban area adjacent to the motorway. Meanwhile we are aware of the model's current limitations, such as the negligence of traffic-induced turbulence as well as physical and chemical transformations of the emitted particles. We anticipate that the method will be further developed and deployed in similar traffic settings when studying traffic-related particle emissions over the years to come.

\section{Appendix A}

\section{Lifetime of small particles due to coagulation}

Nano-sized particles in the atmosphere are subject to enhanced loss processes, notably coagulation with bigger particles. We examined in an exemplary fashion the life-time of $18 \mathrm{~nm}$-particles with respect to Brownian coagulation in the transition regime (Seinfeld and Pandis, 1998) using a sectional aerosol box model. $18 \mathrm{~nm}$ is the diameter of maximum number concentration at roadside. In addition to particle size range measured by SMPS $(10-500 \mathrm{~nm})$, a coarse par-
Table A1. Life times of $18 \mathrm{~nm}$-particles against coagulation, calculated for different statistical levels (percentiles) of the particle size distribution at roadside. $D_{p, \max }$ is the diameter that contributes most to the coagulation rate. Different hygroscopic particle growth factors (GF) simulate dry and humid conditions.

\begin{tabular}{|c|c|c|c|c|c|}
\hline SD level $^{1}$ & Total $N^{2}$ & $D_{p, \max }$ & $t_{0.90}$ & $t_{0.75}$ & $t_{0.50}$ \\
\hline \multicolumn{6}{|c|}{ dry ambient conditions $(G F=1)$} \\
\hline p50 & 20 & $89 \mathrm{~nm}$ & $36 \mathrm{~min}$ & $98 \mathrm{~min}$ & $240 \mathrm{~min}$ \\
\hline p75 & 52 & $89 \mathrm{~nm}$ & $19 \mathrm{~min}$ & $52 \mathrm{~min}$ & $120 \mathrm{~min}$ \\
\hline p95 & 110 & $91 \mathrm{~nm}$ & $10 \mathrm{~min}$ & $26 \min$ & $63 \mathrm{~min}$ \\
\hline p99 & 180 & $96 \mathrm{~nm}$ & $6 \mathrm{~min}$ & $18 \mathrm{~min}$ & $43 \mathrm{~min}$ \\
\hline $\mathrm{p} 99 \star$ & 1400 & $18 \mathrm{~nm}$ & $2 \mathrm{~min}$ & $4 \min$ & $11 \mathrm{~min}$ \\
\hline \multicolumn{6}{|c|}{ wet ambient conditions $(G F=1.4)$} \\
\hline p50 & 20 & $89 \mathrm{~nm}$ & $24 \mathrm{~min}$ & $65 \mathrm{~min}$ & $158 \mathrm{~min}$ \\
\hline p75 & 52 & $89 \mathrm{~nm}$ & $13 \mathrm{~min}$ & $34 \mathrm{~min}$ & $83 \mathrm{~min}$ \\
\hline p95 & 110 & $91 \mathrm{~nm}$ & $6 \mathrm{~min}$ & $17 \mathrm{~min}$ & $41 \mathrm{~min}$ \\
\hline p99 & 180 & $96 \mathrm{~nm}$ & $4 \mathrm{~min}$ & $12 \mathrm{~min}$ & $28 \mathrm{~min}$ \\
\hline 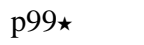 & 1400 & $18 \mathrm{~nm}$ & $1 \mathrm{~min}$ & $3 \min$ & $6 \mathrm{~min}$ \\
\hline
\end{tabular}

${ }^{1}$ statistical size distribution level (p50: 50th percentile etc.)

2 in $10^{3} \mathrm{~cm}^{-3}$.

ticle mode $\left(N=5 \mathrm{~cm}^{-3} ; \sigma=1.72 ; D_{g 0}=1.2 \mu \mathrm{m}\right)$ was prescribed as a potential coagulation sink. (In fact, the life-times were insensitive towards the presence of this particle mode.) The corresponding life-times of $18 \mathrm{~nm}$-particles are shown in Table A1. $t\left(0.90 N_{0}\right)$ indicates, for instance, the time after which the initial particle concentration $N_{0}$ has dropped to $90 \%$ of its initial value. The size distributions p50...p99 correspond to the tri-modal distributions from Table 3. In the additional distribution " $\mathrm{p} 99 \star$ " the concentration of the young Aitken mode was raised by a factor of 10, thereby simulating high concentrations closer to the tailpipe. Calculations were made two relative humidity scenarios, simulated by hygroscopic growth factors (GF) of 1 and 1.4. The higher growth factor simulates grwth of continental accumulation mode particles at $90 \%$ relative humidity. Table A1 shows that under typical roadside conditions (p50, p75, p95) the shortest life-time $t\left(0.90 N_{0}\right)$ was 6 min (under humid conditions), so that the effect of coagulation of $18 \mathrm{~nm}$-particles can be safely neglected for transport times of several minutes.

Acknowledgements. This work was supported by the German Environmental Agency (UBA) project UFOPLAN 204-42-204/03. We thank Dieter Bake from UBA Berlin for his generous support during the preparation and conduction of the field experiment, and his help regarding the supply of auxiliary data. André Sonntag and Korinna König assisted with the particle measurements during the campaign in Berlin, while Ibro Pandzo and Simone Warwel measured and evaluated the traffic volumes. Birgitta Alaviippola acknowledges support by the EU Marie Curie host fellowship (EVK2-CT-2002-57005) coordinated by Alfred Wiedensohler. Parts of the data evaluation for this paper were conducted within 
the European Integrated project on Aerosol Cloud Climate and Air Quality Interactions (EUCAARI), coordinated by the University of Helsinki, Finland.

Edited by: V.-M. Kerminen

\section{References}

Abu-Allaban, M., Coloumb, W., Gertler, A., et al.: Exhaust particle size distribution measurement at the Tuscarora mountain tunnel, Aerosol Sci. Tech., 36, 771-789, 2002.

Ban-Weiss, G. A., McLaughlin, J. P., Harley, R. A., et al.: Longterm changes in emissions of nitrogen oxides and particulate matter from on-road gasoline and diesel vehicles, Atmos. Environ., 42, 220-232, 2008.

Beddows, C. S. and Harrison, R. M.: Comparison of average particle number emission factors for heavy and light duty vehicles derived from rolling chassis dynamometer and field studies, Atmos. Environ., 42, 7954-7966, 2008.

Birmili, W., Stratmann, F., and Wiedensohler, A.: Design of a DMA-based size spectrometer for a large particle size range and stable operation, J. Aerosol Sci., 30, 549-553, 1999.

Birmili, W., Wiedensohler, A., Heintzenberg, J., and Lehmann, K.: Atmospheric particle number size distribution in Central Europe: Statistical relations to air masses and meteorology, J. Geophys. Res., 106, D23, 32005-32018, 2001.

Britter, R. and Hanna, S.: Flow and dispersion in urban areas, Annual Rev. Fluid Mech., 35, 469-496, 2003.

Brunekreef, B., Janssen, N., de Hartog, J., Harssema, H., Knape, M., and van Vliet, P.: Air pollution from truck traffic and lung function in children living near motorways, Epidemiology, 8, 298-303, 1997.

Burtscher, H.: Physical characterization of particulate emissions from diesel engines: a review, J. Aerosol Sci., 36, 896-932, 2005.

Charron, A. and Harrison, R.: Primary particle formation from vehicle emissions during exhaust dilution in the roadside atmosphere, Atmos. Environ., 37, 4109-4119, 2003.

Corsmeier, U., Imhof, D., Kohler, M., et al.: Comparison of measured and model-calculated real-world traffic emissions, Atmos. Environ., 39, 5760-5775, 2005.

Gelencsér, A.: Carbonaceous Aerosol, Springer, Berlin, 350 pp., 2004.

Gramotnev, G., Brown, R., Ristovski, Z., Hitchins, J., and Morawska, L.: Determination of average emission factors for vehicles on a busy road, Atmos. Environ., 37, 465-474, 2003.

HBEFA: The Handbook Emission Factors for Road Transport, INFRAS, Bern, Switzerland, 2.1 edition, 2004.

HEI: Understanding the health effects of components of the particulate matter mix: progress and next steps, Tech. Rep. 4, Health Effects Institute, Boston, MA, 2002.

Hinneburg, D. and Knoth, O.: Non-dissipative cloud transport in Eulerian grid models by the volume-of-fluid (VOF) method, Atmos. Environ., 39, 4321-4330, 2005.

Holmes, N. and Morawska, L.: A review of dispersion modelling and its application to the dispersion of particles: An overview of different dispersion models available, Atmos. Environ., 40, 5902-5928, 2006.
Hueglin, C., Buchmann, B., and Weber, R.: Long-term observation of real-world road traffic emission factors on a motorway in Switzerland, Atmos. Environ., 40, 3696-3709, 2006.

Hussein, T., Puustinen, A., Aalto, P. P., Mäkelä, J. M., Hämeri, K., and Kulmala, M.: Urban aerosol number size distributions, Atmos. Chem. Phys., 4, 391-411, 2004, http://www.atmos-chem-phys.net/4/391/2004/.

Hussein, T., Haämeri, K., Aalto, P., Paatero, P., and Kulmala, M.: Modal structure and spatial-temporal variations of urban and suburban aerosols in Helsinki, Finland, Atmos. Environ., 39, 1655-1668, 2005.

Imhof, D., Weingartner, E., Ordóñez, C., et al.: Real-world emission factors of fine and ultrafine aerosol particles for different traffic situations in Switzerland, Environ. Sci. Technol., 39, 8341-8350, 2005.

Imhof, D., Weingartner, E., Prévôt, A. S. H., Ordóñez, C., Kurtenbach, R., Wiesen, P., Rodler, J., Sturm, P., McCrae, I., Ekström, $\mathrm{M}$., and Baltensperger, $\mathrm{U} .:$ Aerosol and $\mathrm{NO}_{\mathrm{x}}$ emission factors and submicron particle number size distributions in two road tunnels with different traffic regimes, Atmos. Chem. Phys., 6, 22152230, 2006, http://www.atmos-chem-phys.net/6/2215/2006/.

Jamriska, M., Morawska, L., and Mergernse, K.: The effect of temperature and humidity on size segregated traffic exhaust particle emissions, Atmos. Environ., 42, 2369-2382, 2008.

Janhäll, S. and Hallquist, M.: A Novel Method for Determination of Size-Resolved, Submicrometer Particle Traffic Emission Factors, Environ. Sci. Technol., 39, 7609-7615, 2005.

Jones, A. M. and Harrison, R. M.: Estimation of the emission factors of particle number and mass fractions from traffic at a site where mean vehicle speeds vary over short distances, Atmos. Environ., 40, 7125-7137, 2006.

Kean, A., Harley, R., Littlejohn, D., and Kendall, G.: Effects of vehicle speed and engine load on motor vehicle emissions, Environ. Sci. Tech., 37, 3739-3746, 2003.

Ketzel, M., Wåhlin, P., Berkowicz, R., and Palmgren, F.: Particle and trace gas emission factors under urban driving conditions in Copenhagen based on street and roof-level observations, Atmos. Environ., 37, 2735-2749, 2003.

Kim, J., Smorodinsky, S., Lipsett, M., Singer, B., Hodgson, A., and Ostro, B.: Traffic-related air pollution near busy roads: The East Bay Children's Respiratory Health Study, Am. J. Resp. Crit. Care Med., 170, 520-526, 2004.

Kittelson, D.: Engines and Nanoparticles: A Review, J. Aerosol Sci., 29, 575-588, 1998.

Kristensson, A., Johansson, C., Westerholm, R., et al.: Real-world traffic emission factors of gases and particles measured in a road tunnel in Stockholm, Sweden, Atmos. Environ., 38, 657-673, 2004.

Künzli, N., Kaiser, R., Medina, S., et al.: Public-health impact of outdoor and traffic-related air pollution: a European assessment, Lancet, 356, 795-801, 2000.

LUA: Luftreinhalte-/Aktionsplan Bernau bei Berlin - Ermittlung emissionsrelevanter Parameter über die Erfassung von KfzKennzeichen, 105, Landesumweltamt Brandenburg, Potsdam, Germany, 2006.

Mathis, U., Ristimäki, J., Mohr, M., et al.: Sampling conditions for the measurement of nucleation mode particles, Aerosol Sci. Tech., 38, 1149-1160, 2004.

Mayer, A., Kasper, M., Mosimann, T., et al.: Nanoparticle-emission 
of EURO 4 and EURO 5 HDV compared to EURO 3 with and without DPF, SAE transactions, 1, 1-9, 2007.

Morawska, L., Thomas, S., Jamriska, M., and Johnson, G.: The modality of particle size distributions of environmental aerosols, Atmos. Environ., 33, 4401-4411, 1999.

Morawska, L., Jamriska, M., Thomas, S., et al.: Quantification of particle number emission factors for motor vehicles from on-road measurements, Environ. Sci. Tech., 39, 9130-9139, 2005.

Ntziachristos, L., Mamakos, A., Samaras, Z., et al.: Overview of the european Particulates project on the characterization of exhaust particulate emissions from road vehicles: Results for light-duty vehicles, SAE transactions, 113, 1354-1373, 2004.

Olivares, G., Johansson, C., Ström, J., and Hanson, H.: The role of ambient temperature for particle number concentrations in a street canyon, Atmos. Environ., 41, 2145-2155, 2007.

Palmgren, F., Berkowicz, R., Ziv, A., and Hertel, O.: Actual car fleet emissions estimated from urban air quality measurements and street pollution models, Sci. Total. Environ., 235, 101-109, 1999.

Peters, A., Wichmann, H. E., Tuch, T., Heinrich, J., and Heyder, J.: Respiratory effects are associated with the number of ultrafine particles, Am. J. Respir. Crit. Care Med., 155, 1376-1383, 1997.

Pohjola, M., Pirjola, L., Kukkonen, J., and Kulmala, M.: Modelling of the influence of aerosol processes for the dispersion of vehicular exhaust plumes in street environment, Atmos. Environ., 37, 339-351, 2003.

Pope, C. A., Burnett, R. T., Thun, M. J., et al.: Lung cancer, cardiopulmonary mortality, and long-term exposure to fine particulate air pollution, J. Aerosol Med., 287, 1132-1141, 2002.

Ronkko, T., Virtanen, A., Vaaraslahti, K., et al.: Effect of dilution conditions and driving parameters on nucleation mode particles in diesel exhaust: Laboratory and on-road study, Atmos. Environ., 40, 2893-2901, 2006.

Rose, D., Wehner, B., Ketzel, M., Engler, C., Voigtlnder, J., Tuch, T., and Wiedensohler, A.: Atmospheric number size distributions of soot particles and estimation of emission factors, Atmos. Chem. Phys., 6, 1021-1031, 2006,

http://www.atmos-chem-phys.net/6/1021/2006/.

Rosenbohm, E., Vogt, R., Scheer, V., et al.: Particulate size distributions and mass measured at a motorway during the BAB II campaign, Atmos. Environ., 39, 5696-5709, 2005.

Samaras, Z., Ntziachristos, L., Thompson, N., Hall, D., Westerholm, R., and Boulter, P.: Characterisation of Exhaust Particulate Emissions from Road Vehicles (PARTICULATES), Web report, Aristotle University of Thessaloniki, Laboratory of Applied Thermodynamics, available at: http://lat.eng.auth.gr/ particulates, 2005.

Schlünzen, K. H., Hinneburg, D., Lambrecht, M., et al.: Flow and tranport in the obstacle layer: First results of the micro-scale model MITRAS, J. Atmos. Chem., 44, 113-130, 2003.

Schwartz, J., Dockery, D., and Neas, L.: Is daily mortality associated specifically with fine particles?, J. Air Waste Manag., 46, 927-939, 1996.
Seaton, A., MacNee, W., Donaldson, K., and Godden, D.: Particulate air pollution and acute health effects, Lancet, 345, 176-178, 1995.

Seinfeld, J. H. and Pandis, S. P.: Atmospheric Chemistry and Physics: from air pollution to climate change, John Wiley, New York, USA, 2 edition, 1326 pp., 1998.

Spurny, K. R.: Analytical chemistry of aerosols, Science and Technology, Lewis, CRC Press, Boca Raton, USA, 486 pp., 1999.

Vachon, G., Louka, P., Rosant, J., Mestayer, P., and Sini, J.: Measurements of traffic-induced turbulence within a street canyon during the Nantes'99 experiment, Water Air Soil Poll., 2, 127140, 2002.

Vardoulakis, S., Fisher, B., Pericleous, K., and Gonzalez-Flesca, N.: Modelling air quality in street canyons: a review, Atmos. Environ., 37, 155-182, 2003.

Voigtländer, J., Tuch, T., Birmili, W., and Wiedensohler, A.: Correlation between traffic density and particle size distribution in a street canyon and the dependence on wind direction, Atmos. Chem. Phys., 6, 4275-4286, 2006,

http://www.atmos-chem-phys.net/6/4275/2006/.

Wehner, B., Birmili, W., Gnauk, T., and Wiedensohler, A.: Particle number size distributions in a street canyon and their transformation into the urban background: Measurements and a simple model study, Atmos. Environ., 36, 2215-2223, 2002.

Weingartner, E., Keller, C., Stahel, W. A., Burtscher, H., and Baltensperger, U.: Aerosol emission in a road tunnel, Atmos. Environ., 31, 451-462, 1997.

Winklmayr, W., Reischl, G. P., Linde, A. O., and Berner, A.: A new electromobility spectrometer for the measurement of aerosol size distributions in the size range from 1 to $1000 \mathrm{~nm}$, J. Aerosol Sci., 22, 289-296, 1991.

Wissink, A., Chand, K., Kosovic, B., Chan, S., Berger, M., and Chow, F.: Adaptive Urban Dispersion Integrated Model, presentation at the 86th American Meteorological Society Annual Meeting Atlanta, UCRL-PROC-216813, 21, 2005 (downloadable from https://computation.llnl.gov/casc/audim/pube.html)

Zhang, K., Wexler, A., Niemeier, D., et al.: Evolution of particle number distribution near roadways - Part III: Traffic analysis and on-road size resolved particulate emission factors, Atmos. Environ., 39, 4155-4166, 2005.

Zhang, K. M. and Wexler, A. S.: Evolution of particle number distribution near roadways - Part I: analysis of aerosol dynamics and its implications for engine emission measurement, Atmos. Environ., 38, 6643-6653, 2004.

Zhang, K. M., Wexler, A. S., Zhu, Y., Hinds, W. C., and Sioutas, C.: Evolution of particle number distribution near roadways - Part II: the "Road-to-Ambient" process, Atmos. Environ., 38, 66556665, 2004.

Zhu, Y. and Hinds, W.: Concentration and size distribution of ultrafine particles near a major highway, J. Air Waste Manag., 52, 1032-1042, 2002. 